\title{
EFFECT OF AXIAL DEFORMATION CAUSED BY TORSION ON A SOLID STEEL CYLINDER
}

\author{
BY \\ Dawson Forsey \\ B.Eng., Memorial University of Newfoundland and Labrador, St. John's, NL, 2014
}

A project report

presented to Ryerson University

in partial fulfillment of the

requirements for the degree of

Master of Engineering

in the program of

Civil Engineering

Toronto, Ontario, Canada

(C) Dawson Forsey, 2019 


\section{AUTHOR'S DECLARATION}

I hereby declare that I am the sole author of this report. This is a true copy of the report, including any required final revisions.

I authorize Ryerson University to lend this report to other institutions or individuals for the purpose of scholarly research.

I further authorize Ryerson University to reproduce this report by photocopying or by other means, in total or in part, at the request of other institutions or individuals for the purpose of scholarly research.

I understand that my report may be made electronically available to the public. 


\title{
EFFECT OF AXIAL DEFORMATION CAUSED BY TORSION ON A SOLID STEEL CYLINDER
}

\author{
Dawson Forsey, Master of Engineering, 2019 \\ Department of Civil Engineering \\ Ryerson University, Toronto
}

\begin{abstract}
Equations describing the classical theory of applied torsion and axial rotation on a solid cylindrical shaft have been modified by Shirali and Hossain (2019) to derive new theorems, which can take into consideration axial deformation of members. The modified theorems use various empirical parameters to introduce the combined effect of axial force, axial displacement and axial rotation, which is neglected in classical theorems of torsion. Multiple finite element analysis models for solid steel cylindrical members, fixed at one end and subjected to torsion at its free end, were developed to study the effects of torsional loading. The effect of axial deformation/stress developed in the cylinder is analyzed and compared with values predicted by classical and proposed modified theorems (equations). It is shown that the cylinder can shorten or elongate when subjected to torsion. The proposed theorems/equations, based on axial deformation subjected to torsion, provide more accurate predictions of shear stress and axial rotation (angle of twist).
\end{abstract}




\section{ACKNOWLEDGEMENTS}

I would like to thank Dr. Khandaker M. Anwar Hossain for supervising me throughout my studies in the Master of Engineering Program. Without his guidance, I would not have been able to achieve a deep understanding of fundamental engineering principles. He has given me invaluable incites and constructive critiques which have helped refine the contents of this research project.

I would also like to thank Mr. Omid Shirali for contributing to the development of the modified theorem of torsion. I would not have explored this field of study without his inspiration. I would also like to thank Ali Ehsani Yeaganeh, for all his help with modelling in finite element software, ABAQUS.

Finally, I would like to thank my wife Jennifer Hitrec for all her love and support throughout my studies. 


\section{TABLE OF CONTENTS}

AUTHOR'S DECLARATION

ABSTRACT

LIST OF FIGURES _ 'vii

LIST OF TABLES N ix

NOTATIONS $\quad x$

CHAPTER 1 1

$1 \quad$ INTRODUCTION 1

1.1 General

1.2 BACKGROUND 3

1.3 SCOPE AND ObJective OF STUdy 4

1.4 REPORT OUTLINE

\begin{tabular}{ll} 
CHAPTER 2 & 7 \\
\hline
\end{tabular}

$\underline{2}$ DERIVATION OF EQUATIONS DESCRIBING A MODIFIED THEOREM OF TORSION BY SHIRALI AND HOSSAIN (2019) 77

$\begin{array}{lll}2.1 & \text { GENERAL } & 7\end{array}$

2.2 Modified Theorem of Torsion Derived by SHIRAli ANd HosSain (2019) 7

2.2.1 Parameters/Constants $\lambda$, B AND $\gamma \quad 10$

\begin{tabular}{lr} 
CHAPTER 3 & 12 \\
\hline
\end{tabular}

$\underline{3}$ DEVELOPMENT OF FINITE ELEMENT ANALYSIS MODEL FOR A SOLID

\begin{tabular}{lr} 
STEEL CYLINDERS & 12 \\
\hline
\end{tabular}

$\begin{array}{lll}3.1 & \text { GENERAL } & 12\end{array}$

3.2 ABAQUS FE MOdel ASSEmbly $\quad 12$

3.3 Material Property Assignments to Solid Steel Cylinder 13 
3.4 MESH OPTIMIZATION

3.5 Finite Element Torsion StUdy Guidelines/PRotocol 16

\begin{tabular}{lr} 
CHAPTER 4 & 17 \\
\hline
\end{tabular}

$\underline{4}$ STUDY OF THE EFFECTS OF TORSION ACTING AT THE FREE FACE OF A SOLID STEEL CYLINDER CANTILEVER WHILE THE OPPOSITE END OF THE CYLINDER IS FIXED

$\begin{array}{lll}4.1 & \text { GENERAL } & 17\end{array}$

4.2 SIMPLE TORSION STUDY FE RESUlTS 17

4.3 AXial Displacement Caused by Torsion on Face of Solid Cylinder 19

4.4 CONSTANT B VERIFIED BY FE ANALYSIS 23

4.5 CONSTANT $\lambda$ Verified by FE ANALYSIS

4.6 AXIAl Force INDUCED By APPliEd TORQUe ON FIXED Node 25

$\begin{array}{lll}\text { 4.7 } & \text { CONSTANT } \gamma \text { VERIFIED By FE ANALYSIS } & 27\end{array}$

4.8 Shear Stress InduCED by APPLIEd Torque ON CyLINDER FACE 28

4.9 Helical Pattern OF Cylinder 30

\begin{tabular}{lr} 
CHAPTER 5 & 31 \\
\hline
\end{tabular}

$\underline{5}$ CONCLUSIONS AND RECOMMENDATIONS

$\begin{array}{lll}5.1 & \text { GenERAL } & 31\end{array}$

$\begin{array}{lll}5.2 & \text { Conclusions } & 31\end{array}$

5.3 RECOMMENDATIONS FOR FURTHER STUDIES 33

\begin{tabular}{lr} 
APPENDIX A & 34 \\
\hline
\end{tabular}

\begin{tabular}{lr} 
REFERENCES & 48 \\
\hline
\end{tabular} 


\section{LIST OF FIGURES}

Figure 1.1 Axial Displacement Induced by Rotation (Shirali and Hossain 2019)..........2

Figure 1.2 Two Rings Connected with Cables and Helical Pattern Caused by Twist

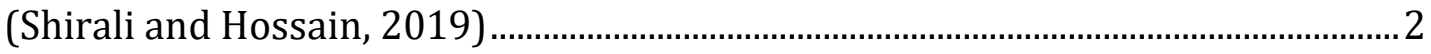

Figure 2.1 Helical Pattern in Twisted Cylinder ……………………………………….........

Figure 3.1 FE Representation of a Cylinder with Optimized Mesh between Discrete

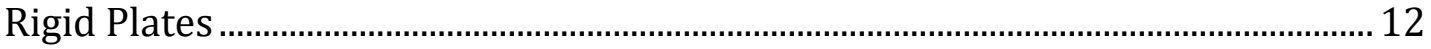

Figure 3.2 Yield and Ultimate Tensile Strength of Steel for ABAQUS.............................13

Figure 3.3 Mesh Length, L, width, $d$ and Edge Spacing,N ................................................ 14

Figure 3.4 Mesh Optimization with constant width $\mathrm{d}$ and length varied - Rotation is maximized at $0.1 \mathrm{rad}$ when $\mathrm{L} / \mathrm{d}$ falls within 1-3 range............................................ 14

Figure 3.5 Mesh Optimization By Edge Spacing - Rotation is maximized at $0.01 \mathrm{rad}$ when AR1 = 3 and edge spacing $\mathrm{N}$ reaches 40 or beyond....................................... 15

Figure 3.6 Mesh Optimization with changing L and d-AR1 = 3 with varying widths

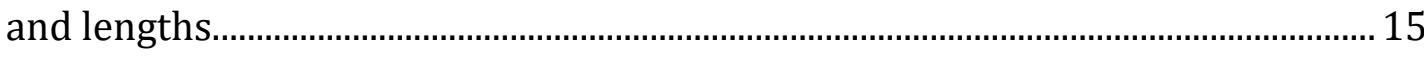

Figure 4.1 Torsion vs Rotation of Cylinder with $\mathrm{R}=0.05$ (left) and R 0.1 (right) ...... 18

Figure 4.2 Rotation vs Torsion P1.5L0.05R ...................................................................... 18

Figure 4.3 Displacement on Front of Cylinder Static Torsion Loading Analysis of a Solid Cylinder.................................................................................................................... 19

Figure 4.4 Axial Displacement (U3) of center node of 1.5L0.05R (left) and 1.5L0.1R (right) for Static Torsion Loading Analysis of a Solid Cylinder ...............................2 20

Figure 4.5 Radius Expansion under Applied Torsion (Scale Factor: 14.97) ................ 20

Figure 4.6 Node Displacement (red dot at top of circle on left is rotated clockwise on

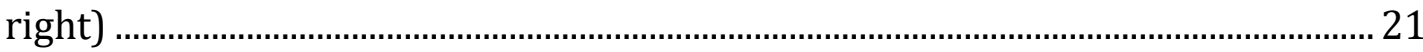

Figure 4.7 Axial Strain vs Axial Rotation for Static Torsion Loading Analysis of a Solid Cylinder 22

Figure 4.8 Axial Strain vs Axial Rotation for Dynamic Torsion Loading test of a Solid Cylinder 22

Figure 4.9 Constant B of Various Geometries 23 
Figure 4.10 Axial Force Induced by Torsion for Static Torsion Loading Analysis of a Solid Cylinder.

Figure 4.11 Test 1.5L0.05R - Displacement vs Axial Force for Static Torsion Loading Analysis of a Solid Cylinder ........................................................................................ 26

Figure 4.12 Max Principle Shear Stress Developed About a Cylinder ............................. 28

Figure 4.13 Shear Stress vs Applied Torsion (1.5L0.05R) for Static Torsion Loading Analysis of a Solid Cylinder .......................................................................................2

Figure 4.14 Shear and Von Mises Stress (MPA) vs Rotation Caused by Torsion for Dynamic Torsion Loading Analysis of a Solid Cylinder .............................................. 30

Figure 4.15 Helical Pattern of Twisted Cylinder.................................................................. 30 


\section{LIST OF TABLES}

Table 1 - Geometric Properties of Various Test Cylinder Compared to Constant B .. 24 


\section{NOTATIONS}

$\begin{array}{ll}\text { A } & \text { Area of Cylinder } \\ \mathrm{B} & \text { Torsion Shortening Coefficient/Parameter/Constant } \\ \mathrm{E} & \text { Modulus of Elasticity } \\ \mathrm{F} & \text { Tension force along each cable due to torsion } \\ \mathrm{f}_{\mathrm{N}} & \text { Axial stress normal to upper ring plane } \\ \mathrm{F}_{\mathrm{N}} & \text { Axial force normal to upper ring plane } \\ \mathrm{f}_{\mathrm{T}} & \text { Axial stress parallel to upper ring plane } \\ \mathrm{F}_{\mathrm{T}} & \text { Axial force parallel to upper ring plane } \\ \mathrm{G} & \text { Shear Modulus } \\ \mathrm{J} & \text { Polar Moment of Inertia } \\ \mathrm{l} & \text { Length of deformed cylinder } \\ \mathrm{L} & \text { Length of undeformed cylinder } \\ \mathrm{N} & \text { Normal Force } \\ \mathrm{r} & \text { Radius of Cylinder } \\ \mathrm{T} & \text { Torsion Moment - Torque } \\ \mathrm{Y} & \text { Strain } \\ \Delta & \text { Length Change of Cylinder } \\ \lambda & \text { Empirical Parameter/Coefficient/Constant } \\ \varphi & \text { Angle of twist about axis of cylinder } \\ \tau & \text { Shear Stress } \\ \sigma & \text { Normal Stress } \\ \theta & \text { Angle between k axes and Axial Force (p') caused by Torsion } \\ \gamma & \text { Empirical Parameter/Coefficient/Constant }\end{array}$




\section{CHAPTER 1}

\section{INTRODUCTION}

\subsection{General}

The classical theory of torsion assumes that when an object, such as a cylinder, is twisted about its center, the displacement of the outermost radius will only displace along the plane of its face. It is assumed that torsion will not cause positive or negative displacement normal to the plane. In other words, it is assumed in classical theory that torsion can neither elongate nor shorten an object in pure torsion and the plane will remain plane. Axial rotation due to torsion of a cylinder and shear stress on the cylinder (as derived in Eqs. 1 and 2, respectively), are not related to axial displacement (Eq. 3) (Hibbeler 2011).

$$
\begin{gathered}
\varphi=\frac{\mathrm{TL}}{\mathrm{GJ}} \\
\tau=\frac{T c}{J} \\
\Delta=\frac{N L}{A E}
\end{gathered}
$$

Where $\varphi$ is the angle of twist/rotation (Fig. 1.1), $\mathrm{T}$ is Torsion applied on face of cylinder, $\mathrm{L}$ is length of cylinder, $\mathrm{N}$ is the axial force, $\mathrm{A}$ is area of cylinder face, $\mathrm{c}$ is radius of cylinder face, $J$ is polar moment of inertia of the cylinder, and $E$ is the modulus of elasticity of the cylinder material.

In a technical report by Shirali and Hossain (2019), it is assumed that torsion causes axial force and displacement and they derived modified theorems of torsion related to axial twist of a solid cylinder based on that assumption. The equations describing angle of twist, axial displacement, axial force, and torsion have all been modified using 
functions based on the helix vector equations and added coefficients to describe axial shortening related to rotation (Shirali and Hossain 2019). The modified theorem of torsion and its derivation are further described in Chapter 2.

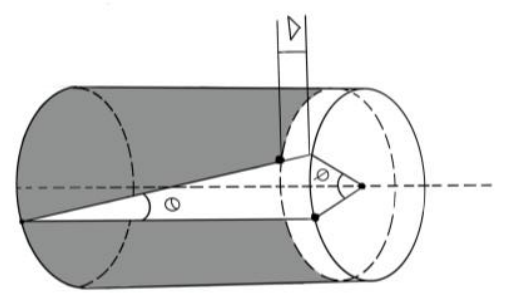

Figure 1.1 Axial Displacement Induced by Rotation (Shirali and Hossain 2019).

The helical pattern is recognized in other forms of twisting. For instance, when a wet cloth is wrung, it is being twisted. The cloth develops a tension force, pulling the hands together, while shortening in length. The same effect is believed to occur with a solid steel member subjected to torsion... Tension effect is illustrated by taking two rings connected by cables (Figure 1.2). The bottom ring is fixed at the base and torsion is applied to the top ring which is free to rotate. When torsion is applied each cable will develop tension as the top of the cables are displaced rotationally. The rotation of the top ring will create a helical pattern in the strings as they resist elongation.
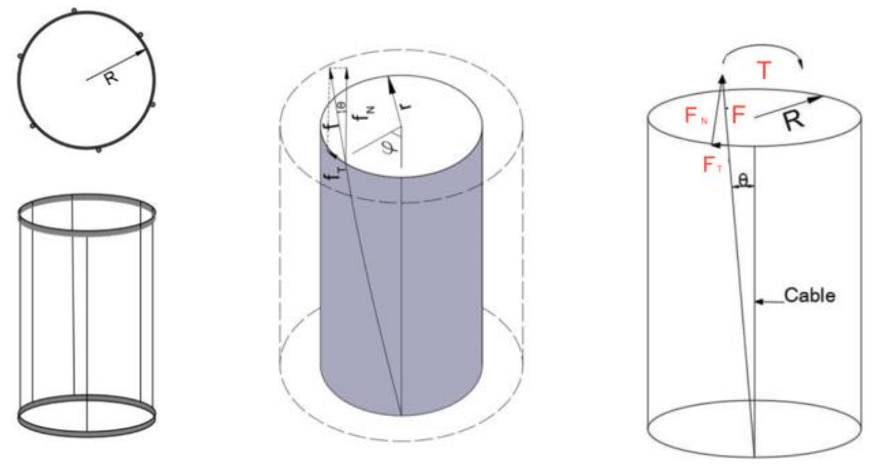

Figure 1.2 Two Rings Connected with Cables and Helical Pattern Caused by Twist (Shirali and Hossain, 2019) 
The force of the torsion is transferred into two components in the cable. A force normal to the ring $\left(\mathrm{F}_{\mathrm{N}}\right)$ and a force parallel to the ring $\left(\mathrm{F}_{\mathrm{T}}\right)$ is generated in the cable. The normal force in the cable is the generated as it resists the moment in tension. Since this force is predicted to act normal to the axes it is assumed to cause axial deformation. It is assumed that the tension in the material will cause axial shortening along line $\mathrm{F}_{\mathrm{N}}$ (Shirali and Hossain, 2019).

\subsection{Background}

Previous research has shown that when a steel bar is rotated, and the length of the specimen is kept constant, an axial force is induced. Oppositely when a bar is rotated, and the length is not fixed, it will change under torsion. The latter was described by Poynting in 1909 and 1912 that a metal bar would increase in length when twisted in the plastic range, and the elongation was linearly proportional to the square of twist (The Poynting Effect) (Billington, 1977).

Many studies were conducted for a variety of materials indicating that there was a general trend in terms of force and length development. They either exhibit compression/lengthening under hot site conditions or tension/shortening in room temperature. Experiments with aluminum showed no lengthening at hot or room temperatures (Montheillet et al., 1984).

When the metal bars or tubes were twisted beyond their elastic limit and plastically deformed that deformation was characterized as the Swift Effect. The length of the rod elongates with increasing strain and more specifically strain hardening of steel (Billington, 1977). The study by Montheillet et al. concludes that axial forces and length increase is caused by development of specific crystallographic textures via high rates of work hardening (Montheillet et al., 1984). The effect of strain hardening is beyond the scope of this study but should be explored further using ductile damage parameters in the finite element analysis. 


\subsection{Scope and Objective of Study}

The purpose of this study it is to analyse the effects of torsion applied to various solid cylinders using finite element (FE) analysis software, ABAQUS, and compare the results with predicted values using classical theory and the modified theorems derived by Shirali and Hossain (2019) discussed further in Chapter 2. These modified torsion equations describe axial angle of twist, axial displacement, axial force, and torsion. Various empirical parameters $(B, \lambda$ and $\gamma)$ are introduced in these equations to introduce the effect of axial deformation through FE modeling using ABAQUS. The goal of the finite element analyses is to confirm the existence/adequacy of such parameter/constants and how they affect the modified theorem of torsion. The study has been carried out with the following objectives:

- Develop FE models of solid steel cylinders of varying geometries using software (ABAQUS).

- Apply geometrical and linear elastic material properties to the steel cylinder for static analysis.

- Apply geometrical and non-linear plastic material properties to the steel cylinder for a dynamic analysis.

- Create a study where torsion is acting at the free face of a solid steel cylinder cantilever while the opposite end of the cylinder is fixed.

- Predict axial rotation, and shear stress values based on classical theory of torsion.

- Collect axial rotation, axial displacement and stress data of the cylinder subjected to torsional loading from FE models.

- Determine the value of empirical parametric constants: $B, \lambda$, and $\gamma$, presented in the modified theorem of torsion based on the relationship 
between axial rotation and axial displacement (derived in Chapter 2), using results collected from the FE models.

- Define a new equation for rotation/angle of twist $(\varphi)$ using newly validated constants $\mathrm{B}, \lambda$, and $\gamma$.

- Compare axial rotation, axial displacement and shear stress derived from FE models with those predicted from classical and modified theoretical equations.

- Compare axial rotation, axial displacement and shear stress values derived from elastic (linear) steel cylinder model to those obtained from plastic (non-linear) FE model.

\subsection{Report Outline}

This project report contains five chapters. Chapter $\mathbf{1}$ gives a general overview of the background research and conceptualization for the modified torsion theorem. Chapter 2 further describes the derivation of the modified theorem of torsion and the empirical parameters/constants used to account for axial displacement, axial force and angle of twist.

Chapter 3 describes the development of FE models for solid steel cylinders with varying geometric and material properties. The cylinder has specific assembly and boundary conditions. Two types of FE analysis models are generated to study the effects of linear elastic and non-linear (plastic) material properties of steel cylindrical member subjected to torsion. The mesh size of the cylinder is optimized based on maximized axial rotation of the cylinder. Static and dynamic analyses are conducted for elastic and plastic models, respectively.

Chapter 4 describes FE models used to study the effects of torsion acting at the free face of a solid steel cylinder cantilever that is fixed on the opposite end. The classical 
theory is used to predict values of axial rotation, shear stress and torsion. The models for the cylinders are analysed and the results regarding axial rotation, axial displacement, and shear stress, is compared with those obtained from classical theories. Results from the FE analysis of a non-linear plastic steel cylinder are compared with those obtained from elastic FE models. Empirical parameter/constants: $\mathrm{B}, \boldsymbol{\lambda}$ and $\gamma$, are verified in the elastic analysis of cylinders and modified equations are derived for axial rotation (angle of twist) with description of relationship between axial force and axial displacement.

Chapter 5 presents conclusions of this study and suggests recommendations for future research. 


\section{CHAPTER 2}

\section{DERIVATION OF EQUATIONS DESCRIBING A MODIFIED THEOREM OF TORSION BY SHIRALI AND HOSSAIN (2019)}

\subsection{General}

This chapter reviews the derivation of equations used to describe the relationship between axial rotation of a solid steel cylinder subjected to torsion and the induced axial displacement caused by rotation at the face of the cylinder. Empirical parameters/constants: $B, \lambda$, and $\gamma$ are implemented to account for axial displacement that is not accounted for in classical torsion theory. Axial rotation/twist is related to axial displacement through introducing parameter B. The classical torsion equation for axial rotation of a solid cylinder is also modified using parameters/constants $\lambda$ and $\gamma$.

\subsection{Modified Theorem of Torsion Derived by Shirali and Hossain (2019)}

If a line is drawn from the base of the cylinder to the free end and then subject to torsion, the displacement is assumed to follow a helical pattern (Figure 2.1). The modified theorem of torsion is thus based on functions of helical equations. A technical report found in appendix A, derives the equations for axial force and axial displacement related to torsion (Shirali and Hossain, 2019).
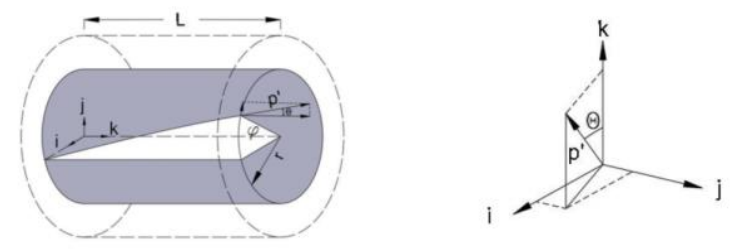

Figure 2.1 Helical Pattern in Twisted Cylinder 
The equation expressing the pattern of the new curved line is a function of Helix Equilibrium. $\mathrm{p}$ describes the position of the node ( $\mathrm{x}, \mathrm{y}, \mathrm{z}$ coordinates) on the edge of the circle that has rotated along with $\varphi$ :

$\mathrm{x}=\mathrm{Ar} \operatorname{Cos}(\gamma \varphi)$

$\mathrm{y}=\operatorname{Ar} \operatorname{Sin}(\gamma \varphi)$

$\mathrm{z}=\mathrm{z}_{1}+\mathrm{B} \varphi^{\lambda}$

When expressed as a vector, it can be shown as:

$\vec{p}=\operatorname{ArCos}(\gamma \varphi) \vec{\imath}+\operatorname{ArSin}(\gamma \varphi) \vec{\jmath}+\left(z_{1} B \varphi^{\lambda-1)}\right) \vec{k}$

$p^{\prime}$ is the tangent vector of $\mathrm{p}$.

$\overrightarrow{p^{\prime}}=-\gamma \operatorname{ArSin}(\gamma \varphi) \vec{\imath}+\gamma \operatorname{ArSin}(\gamma \varphi) \vec{\jmath}+\left(B \lambda \varphi^{\lambda-1)}\right) \vec{k}$

Torsion is assumed to impose a force along p'. The coefficients $\lambda$, B and $\gamma$ are implemented in the equations as empirical parameters/constants that account for length effects due to axial elongation in the cylinder as it rotates/twists. The function is hypothesized to be a power function although it is not clear whether the relationship between rotation and axial displacement is linear or exponential. These constants/parameters are confirmed in the FE analysis study for solid steel cylinders subjected to torsion in Chapter 3.

The stress $\mathrm{f}_{\mathrm{T}}$ is parallel to upper ring plane:

$f_{T}=\frac{\gamma r F}{\sqrt{(\gamma R)^{2}+\left(\mathrm{B} \lambda \varphi^{\lambda-1}\right)^{2}}}$

Torsion (T) can be expressed in terms of $\mathrm{f}_{\mathrm{T}}$ : 


$$
\begin{aligned}
& \mathrm{T}=\int_{0}^{R} 2 \pi f_{T} r d r \\
& \mathrm{~T}=\int_{0}^{R} 2 \pi \frac{\gamma r F}{\sqrt{(\gamma R)^{2}+\left(\mathrm{B} \lambda \varphi^{\lambda-1}\right)^{2}}} r d r \\
& \mathrm{~T}=\frac{R^{4} \pi \gamma F}{\sqrt{(\gamma R)^{2}+\left(\mathrm{B} \lambda \varphi^{\lambda-1}\right)^{2}}}
\end{aligned}
$$

The axial force is normal to the cross section and expressed as N. In Appendix A, it is shown that the axial force is parallel with vector tangent $p^{\prime}$ and is inversely related to the axial displacement, $\Delta$.

$$
\begin{aligned}
& f_{N}=\frac{B F}{\sqrt{(\gamma R)^{2}+\left(\mathrm{B} \lambda \varphi^{\lambda-1}\right)^{2}}} \text { where } f_{N}=\sigma \\
& \mathrm{N}=\int_{0}^{R} 2 \pi f_{N} d r \\
& \mathrm{~N}=\int_{0}^{R} 2 \pi \frac{B F}{\sqrt{(\gamma R)^{2}+\left(\mathrm{B} \lambda \varphi^{\lambda-1}\right)^{2}}} r d r \\
& \mathrm{~N}=\frac{R^{2} B F}{\sqrt{(\gamma R)^{2}+\left(\mathrm{B} \lambda \varphi^{\lambda-1}\right)^{2}}}
\end{aligned}
$$

By relating equations 11 and 15, it is possible to express torsion as it relates to normal force, where $\mathrm{T}$ is equal to the maximum torsion at the outer radius, $\mathrm{R}$ :

$T=\frac{\gamma}{2\left(\mathrm{~B} \lambda \varphi^{\lambda-1}\right)} R^{2} N$

In summary, Shirali and Hossain (2019) confirm that torsion will cause an axial force and that force will cause axial displacement on the solid cylinder. The axial force is predicted to cause the cylinder to shorten in axial tension. 


\subsubsection{Parameters/Constants $\lambda$, B and $\gamma$}

Once the torsion equation $\mathrm{T}$ is found, it is possible to relate torsion to axial displacement as a function of the rotation introducing B:

$$
\begin{aligned}
& \Delta=B \varphi^{\lambda} \\
& \Delta=\frac{N L}{A E} \\
& B=\frac{N L}{A E \varphi^{\lambda}}
\end{aligned}
$$

Substituting equations 19 into equation 16 :

$$
\begin{aligned}
& T=\frac{\gamma \varphi}{2\left(\lambda \mathrm{NL} / \mathrm{AE} \varphi^{\lambda}\right) \varphi^{\lambda-1}} R^{2} N \\
& T=\frac{\gamma \varphi}{2(\lambda \mathrm{L})} A E R^{2}, \text { where } A=\pi R^{2} \\
& T=\frac{\gamma \varphi}{2(\lambda \mathrm{L})} \pi R^{4}, \text { where } J=\pi R^{4} / 2 \\
& \varphi=\frac{\lambda \mathrm{TL}}{\gamma \mathrm{EJ}}, \text { where } E=G 2(1+v) \\
& \varphi=\frac{\mathrm{TL}}{\mathrm{GJ}} \frac{\lambda}{\gamma 2(1+v)}
\end{aligned}
$$

As previously mentioned, constants $\lambda, \mathrm{B}$ and $\gamma$ are yet to be confirmed in the field. It is shown that axial rotation $\varphi$ is related to the classical equation, $\varphi=\frac{\mathrm{TL}}{\mathrm{GJ}}$ (Hibbeler 2011) but with an added factor expressed as $\lambda / \gamma 2(1+v)$, to account for effect of axial displacement. The intent of this study is to confirm if there is a relationship between axial displacement and angle of twist and if these constants are valid in the model. It is assumed that $\gamma$ is a coefficient which may relate to thermal stress or dynamic 
rotational force. The Poisson ratio, $v$ is assumed to be 0.3 for steel as it is an isotropic linear elastic material.

Equation for $\gamma$ can be derived as:

$\gamma=\frac{\mathrm{TL}}{\mathrm{GJ}} \frac{\lambda}{\varphi 2(1+v)}$

A study, using FE software ABAQUS, is conducted to investigate the relationship between axial displacement and the angle of twist generated by torsion. FE model data are used to also investigate to evaluate the need of introducing a constant to take into account the effect of axial shortening or lengthening. The relationship between $\Delta$ and $\varphi$ and axial force $\mathrm{N}$ is explored as torsion loading is increased. 


\section{CHAPTER 3}

\section{DEVELOPMENT OF FINITE ELEMENT ANALYSIS MODEL FOR A SOLID STEEL CYLINDERS}

\subsection{General}

The finite element (FE) analysis software chosen for this study is ABAQUS. FE models of various cylinder lengths and radii are developed for analyses. The cylinder is assembled between to discrete rigid plates. One plate is used to fix the cylinder at one end. The second plate is used to apply torsion to the other face of the cylinder. In each case, model mesh is optimized based on maximization of axial rotation. Two types of analysis are created in the FE program. The first is a static linear analysis for elastic solid steel cylinder. The second is a dynamic non-linear analysis for a plastic steel cylinder.

\subsection{ABAQUS FE Model Assembly}

The assembly consists of a steel cylinder connected to two square plates at each flat face of the cylinder (Fig. 3.1). The cylinder was assigned steel material properties as discussed in section 3.3. Each face of cylinder was tied to a square plate defined as discrete rigid. These plates are infinitely rigid and transfer all loads and displacement directly from the plate onto the cylinder surface.

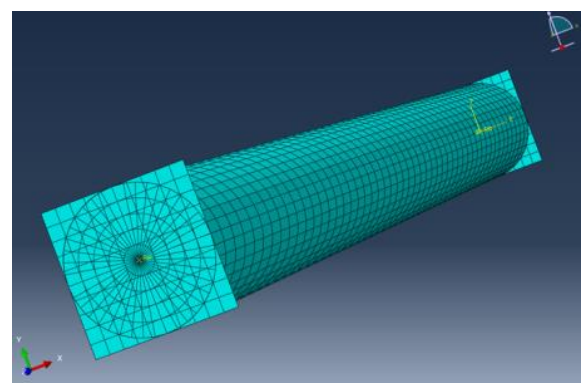

Figure 3.1 FE Representation of a Cylinder with Optimized Mesh between Discrete Rigid Plates 
For example, the designation FE model 1.5L0.05R indicates a cylinder of length, $\mathrm{L}=$ $1.5 \mathrm{~m}$, radius $\mathrm{R}=0.05 \mathrm{~m}$ with plate height and width as $0.1 \mathrm{~m} \times 0.1 \mathrm{~m}$. Boundary condition of fixed end of plate is set as ENCASTRE (U1=U2=U3=0 and $\mathrm{UR} 1=\mathrm{UR} 2=\mathrm{UR} 3=0$ ). The cylinder is tied to the fixed plate ideally as a cantilever. Specified torsional loading s applied to the reference point of the rigid plate at the face of the free end.

\subsection{Material Property Assignments to Solid Steel Cylinder}

The aim of the material assignment was to create a compressible elastic solid with the same properties of common steel. Steel was given a Modulus of Elasticity, E $=200$ $\mathrm{GPa}$, a Poisson's Ratio, $v=0.3$, a Shear Modulus, $\mathrm{G}=76.923 \mathrm{GPa}$ and density of steel $=$ $7870 \mathrm{~kg} / \mathrm{m}^{3}$.For the model intended to be analysed using non-linear plastic steel properties, steel was assumed to be commercial 300W (specification) to simulate a practical material that would be economical and readily available for laboratory testing and analysis. To mimic non-linear behaviour, the steel was given plastic stress and strain values in accordance with this grade of steel (Figure 3.2):

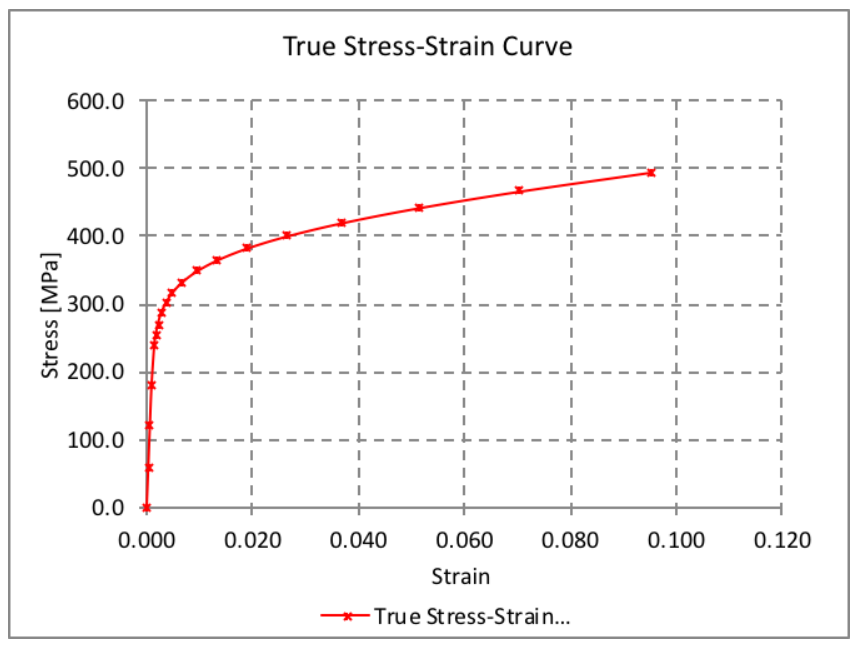

Figure 3.2 Yield and Ultimate Tensile Strength of Steel for ABAQUS 


\subsection{Mesh Optimization}

The cylinder mesh was refined in three directions to determine the maximum mesh size required to achieve its maximum rotation before the mesh refinement became redundant. Cylinder dimensions are expressed as width, $d$ ( $x$ direction), seed length, $\mathrm{L}$ ( $\mathrm{z}$ direction) and edge spacing, $\mathrm{N}$ (about the circumference of the circle) (Figure 3.3). The aspect ratio is thus defined in 3 ways for a 3D cylinder: AR1 $=L / d, A R 2=$ $\mathrm{L} / \mathrm{N}, \mathrm{AR} 3=\mathrm{d} / \mathrm{N}$.

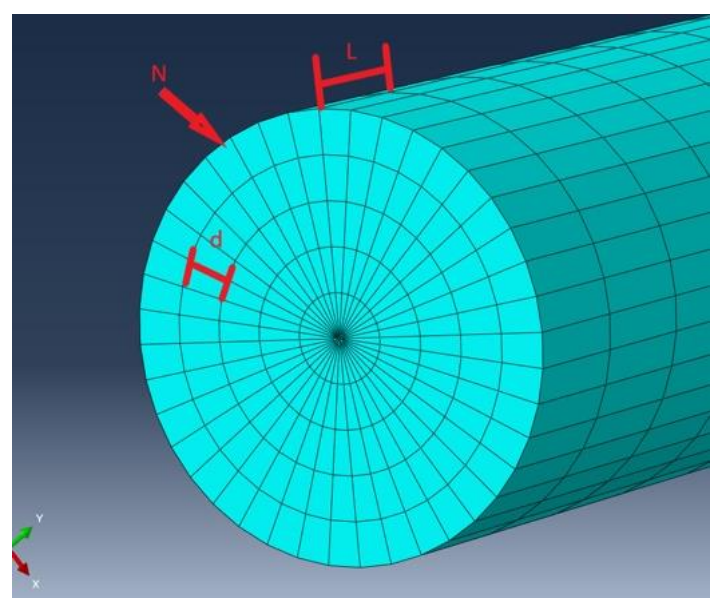

Figure 3.3 Mesh Length, L, width, $d$ and Edge Spacing, $N$

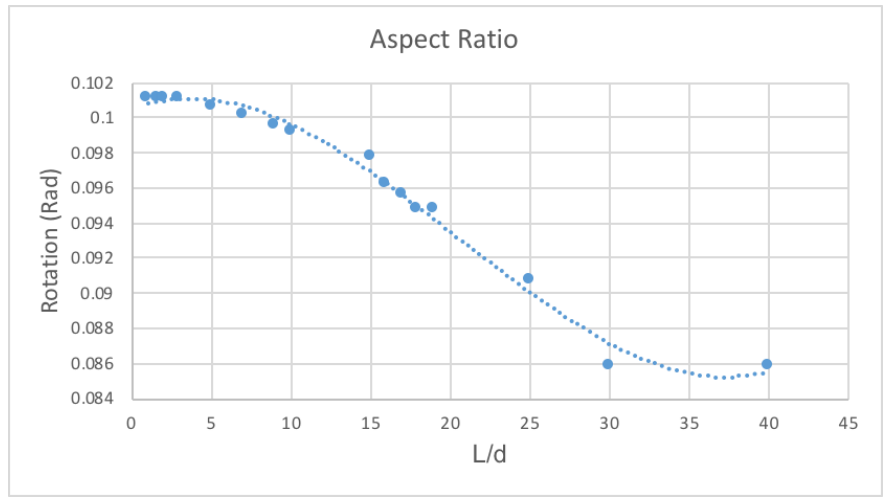

Figure 3.4 Mesh Optimization with constant width d and length varied - Rotation is maximized at 0.1 rad when $L / d$ falls within 1-3 range. 


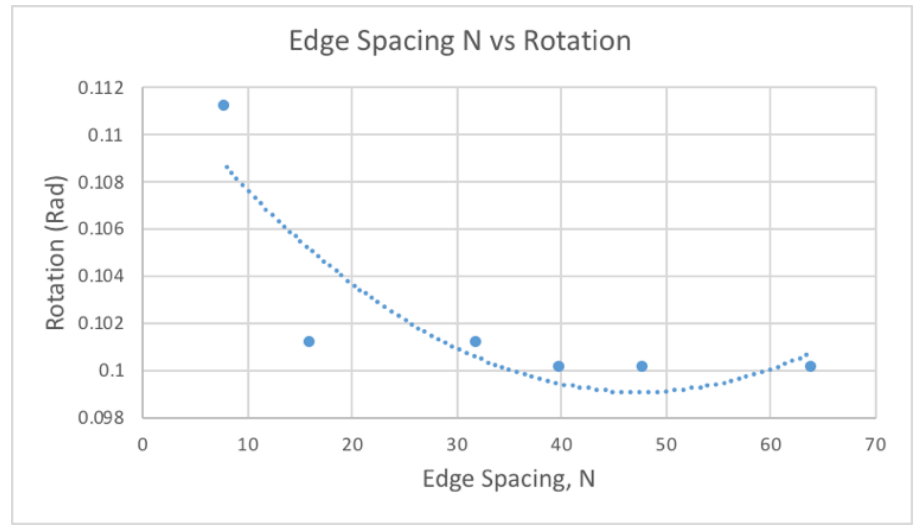

Figure 3.5 Mesh Optimization By Edge Spacing - Rotation is maximized at $0.01 \mathrm{rad}$ when AR1 = 3 and edge spacing $N$ reaches 40 or beyond.

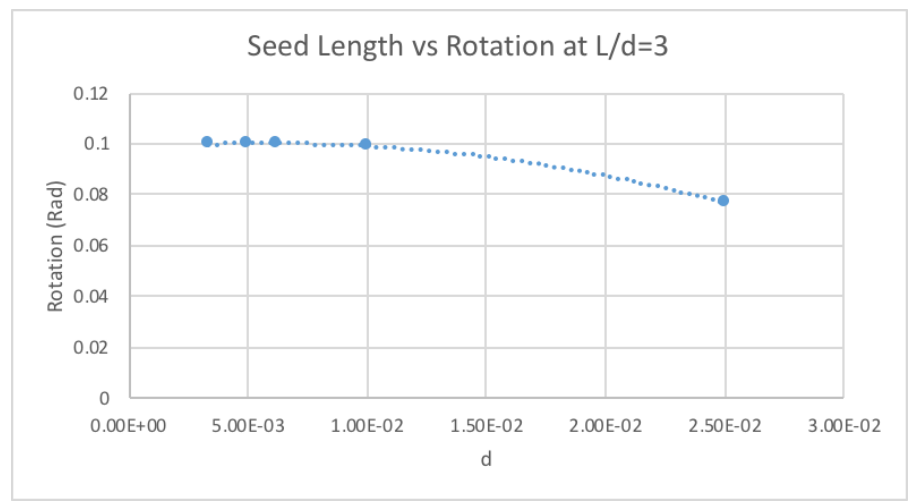

Figure 3.6 Mesh Optimization with changing L and d-AR1 = 3 with varying widths and lengths.

For a $1.5 \mathrm{~m}$ long cylinder with $0.05 \mathrm{~m}$ radius has a seed length of $0.03 \mathrm{~m}(3 \mathrm{R} / 5)$, a width of $0.01 \mathrm{~m}(\mathrm{R} / 3$ ), and edge spacing of 40 (Figure 3.3-3.6) and these ratios are obtained: $\mathrm{AR} 1=3, \mathrm{AR} 2=0.00075$ and AR3 $=0.00025$. The center circle mesh was assigned to sweep as a wedge to provide uniform division at the center and reduce stresses caused by irregular mesh at the center.

Figure 3.7 shows mesh optimization with constant width $d$ when length varied (effect of $\mathrm{L} / \mathrm{d}$ on rotation). Rotation is maximized at $0.1 \mathrm{rad}$ when $\mathrm{L} / \mathrm{d}$ falls within 1 3 range. Figure 3.8 shows mesh optimization by edge spacing. Rotation is 
maximized at $0.01 \mathrm{rad}$ when AR1 $=3$ and edge spacing $\mathrm{N}$ reaches 40 or beyond. Fig. 3.6 shows that as L increased and d decreased, rotation began to reach maximization for $\mathrm{d}$ between 0.01 and 0.05 . Optimum mesh size defined by L/D and $\mathrm{N}$ is used in FE models which maximizes and stabilizes the rotation as confirmed from the mesh optimization study.

\subsection{Finite Element Torsion Study Guidelines/protocol}

For a linear elastic solid steel cylinder, a static loading analysis was performed on multiple cylinders of various geometries. Torsion was applied to the discrete rigid place under a 0.1 second time period, 1 increment and a time step of 0.1 s. The loading began at $10 \mathrm{kNm}$ and data was collected after model generation was complete. Then the applied torsion was reassigned with a new torsion value and the static load analysis was run again for analysis. This process repeated in increasing increments of $10 \%$ of max torsion until $100 \mathrm{kNm}$ was applied.

For a non-linear plastic steel solid cylinder, a dynamic loading analysis was performed under a 1 second time period, 50 increments and a time step of $0.02 \mathrm{~s}$. The torsion was applied in increasing increments of $2 \%$ of max torsion until $100 \mathrm{kNm}$ was reached without resetting load as required in the static analysis.

Analysis models are named based on cylinder length, L and radius, R. FE models include 2.0L0.05R, 1.5L0.05R, 1.5L0.075R, 1.5L0.1R, 1.0L0.05R, 0.5L0.05R, and 0.25L0.05R. 


\section{CHAPTER 4}

\section{STUDY OF THE EFFECTS OF TORSION ACTING AT THE FREE FACE OF A SOLID STEEL CYLINDER CANTILEVER WHILE THE OPPOSITE END OF THE CYLINDER IS FIXED}

\subsection{General}

The FE models were used to study the effects of torsion acting at the free face of a solid steel cylinder cantilever while the opposite end of the cylinder was fixed. The nodal axial force, axial displacement, and shear stress developed at the face of the cylinder were analyzed. The FE study was conducted to confirm if the applied torsion induced the same torsional stress as predicted using the modified torsion theorem and if any, axial tension/shortening or compression/elongation occurred due to axial rotation. The classical theory of torsion was also used to predict values of axial rotation and shear stress. Values obtained from FE models were are compared with those predicted by classical theory and modified theory. Values of parameters/constants $\mathrm{B}, \lambda$, and $\gamma$ (introduced in modified theory) were derived through analysis of elastic steel cylinders and a modified equations for axial displacement was derived. Additionally, a relationship between axial force and axial displacement was described. FE results from the analysis of a non-linear plastic steel cylinder models were compared with those obtained from linear elastic models.

\subsection{Simple Torsion Study FE Results}

The node at the center of the cylinder on the face of free end was selected as a reference point to monitor the rotation due to axial load. As the torsion was applied to the free-face of the cylinder, rotation increased. Rotation showed a linear relationship with torsion (Figure 4.1). AB_ROT represented the ABAQUS FE model ABAQUS values and Class_ROT represented values predicted by classical theory. The 
linear FE model shows $99.09 \%$ convergence with the classical theory in predicting rotation (angle of twist).
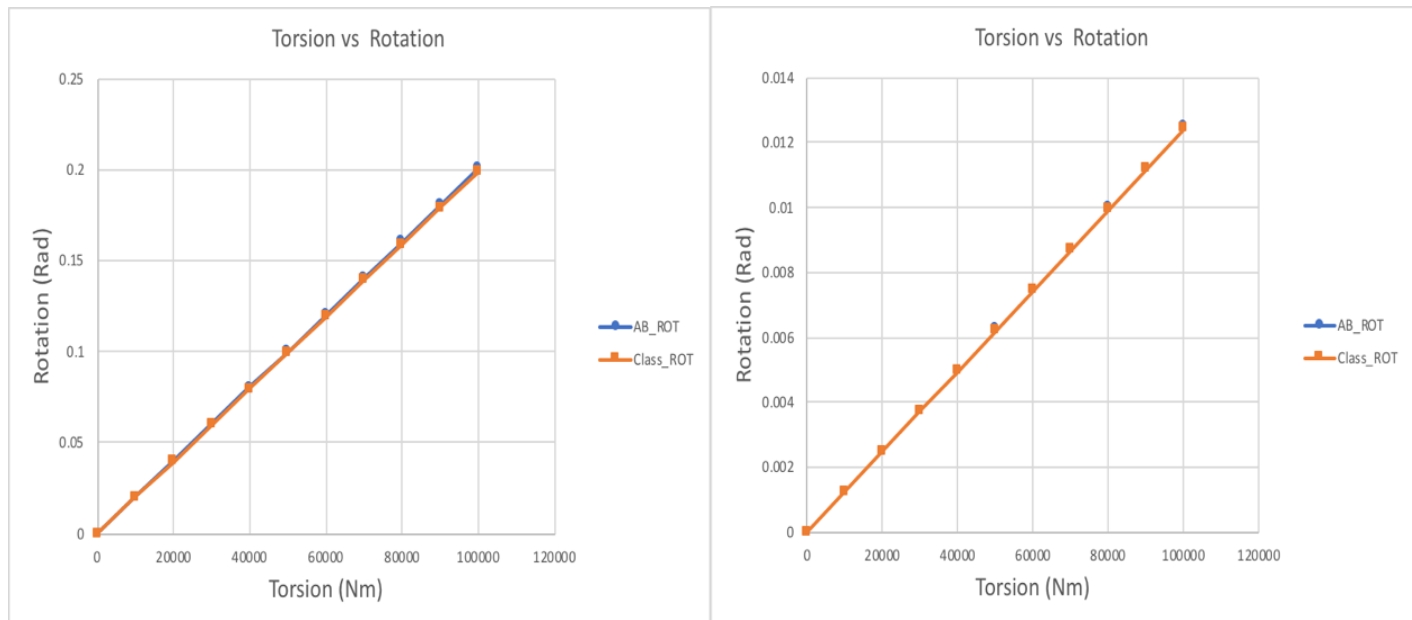

Figure 4.1 Torsion vs Rotation of Cylinder with $R=0.05$ (left) and $R 0.1$ (right)

Non-linear FE dynamic model using steel plastic yield and strain properties exhibited linear torque-angle of twist (rotation) relationship up to steel yield strength (similar to classical theory) and beyond yield point, the rotation was increased exponentially as expected (Fig. 4.2). Furthermore, the rate of rotation accelerated after elastic yield limit and surpassed $0.247 \mathrm{rad}$ when torque reached $52 \mathrm{kNm}$.

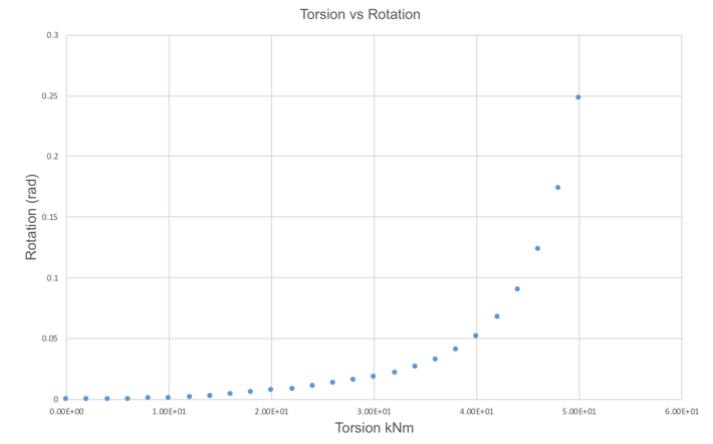

Figure 4.2 Rotation vs Torsion P1.5L0.05R 


\subsection{Axial Displacement Caused by Torsion on Face of Solid Cylinder}

The cylinder face was shown to warp overall where the upper left quarter section of the face of the circle displaced negatively along the $\mathrm{z}$ axis and the lower right quarter section of the face of the circle displaced positively. This is presented in Fig. 4.2 through illustrating the development of U3 (z-direction) displacement. The solid cylinder was analysed with a discrete rigid plate tied to the front surface plane (Figure 4.3).

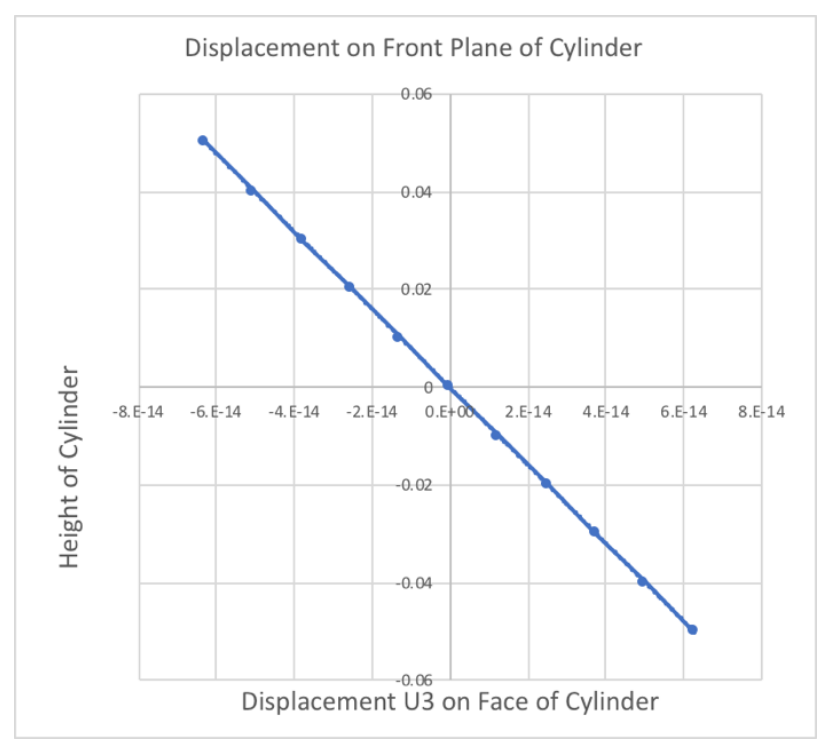

Figure 4.3 Displacement on Front of Cylinder Static Torsion Loading Analysis of a Solid Cylinder

To avoid the effects of warping, displacement U3 was recorded at the center node of the cylinder, at the reference point of rotation. It was shown that the cylinder in some FE models, elongated along the $\mathrm{z}$ axis $(1.5 \mathrm{~L} 0.1 \mathrm{R}$ and 1.0L0.05R) and shortened in other cylinder models (1.5L0.1R, 2.0L0.05R and 1.5L0.075R). The axial elongation and shortening increased linearly with torque and rotation (Figure 4.4). 

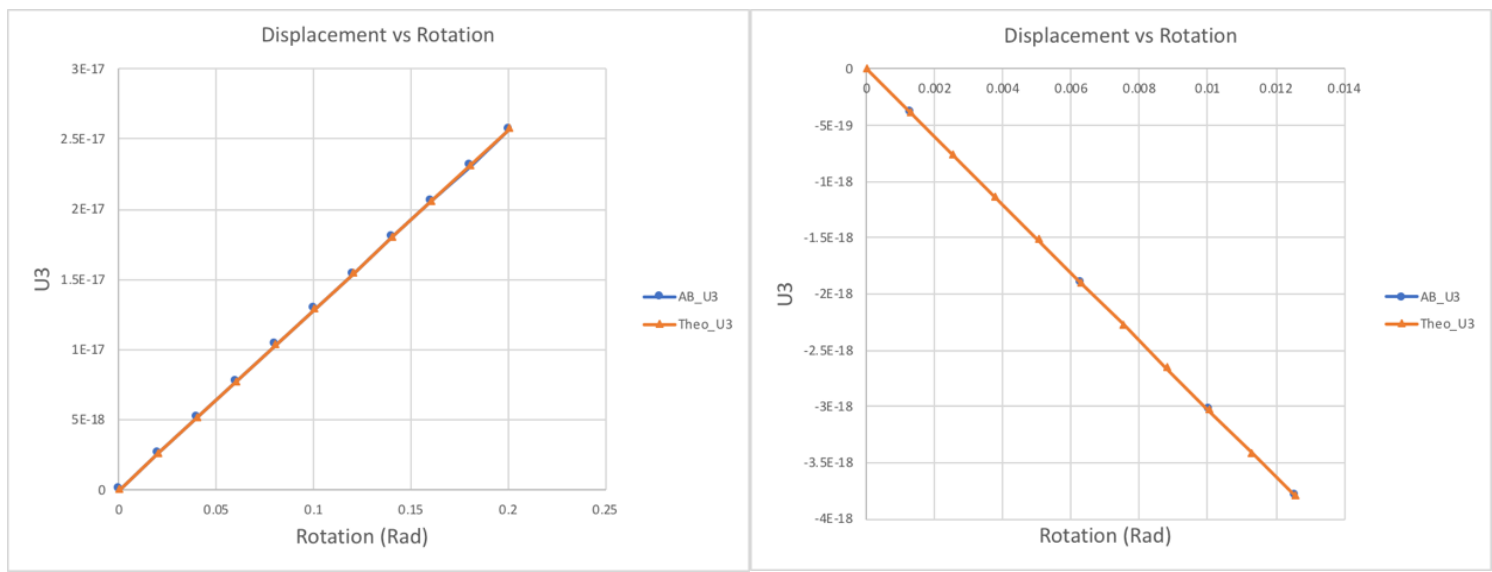

Figure 4.4 Axial Displacement (U3) of center node of 1.5L0.05R (left) and 1.5L0.1R (right) for Static Torsion Loading Analysis of a Solid Cylinder

The reason for warping at the face of the cylinder may be attributed to the interaction of force with the face of the cylinder and non-uniform distribution of the torsional loading on the surface of the cylinder. It might also be due to the mesh size used in the model, the aspect which should be investigated further.

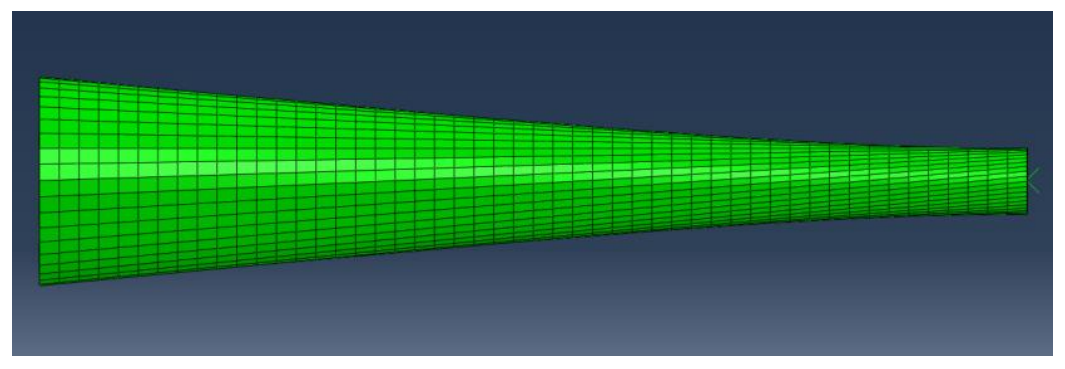

Figure 4.5 Radius Expansion under Applied Torsion (Scale Factor: 14.97)

Aside from warping, the simple torsion also caused the radius of the cylinder to expand as torque increased in the analysis (Figure 4.5). For 1.5L0.05R model, the diameter expanded by $2 \mathrm{~mm}$ at a torsion of $100 \mathrm{kNm}$. When the radius expanded, the length $L$, between fixed and free end of cylinder, increased. . To measure this type of strain on the cylinder, a specific point was chosen at the top of the free ended cylinder. Node displacement was recorded and the final position was noted. It was determined 
that the curve created by the cylinder expansion along the $\mathrm{z}$ axes was negligible. Therefore, the new length of the cylinder is the distance from the fixed end of the cylinder to the displaced free end. The elongated length (l), displacement (?) and strain $(\mathrm{Y})$ were calculated as per the following equations:

$$
\begin{aligned}
& \mathrm{l}=\sqrt{\left(x_{1}-x_{3}\right)^{2}+\left(y_{1}-y_{3}\right)^{2}+\left(z_{1}-z_{3}\right)^{2}} \\
& \Delta=l-L \\
& Y=\Delta / L
\end{aligned}
$$

Where $\left(\mathrm{x}_{1}, \mathrm{y}_{1}, \mathrm{z}_{1}\right)$ is fixed end origin $(0,0.05,0),\left(\mathrm{x}_{2}, \mathrm{y}_{2}, \mathrm{z}_{2}\right)$ is free node origin $(0,0.5,1.5)$, and $\left(\mathrm{x}_{3}, \mathrm{y}_{3}, \mathrm{Z}_{3}\right)$ position of the displaced free node. The displacement $\Delta$ is the difference between original ( $\mathrm{L}$ ) and final length (l).

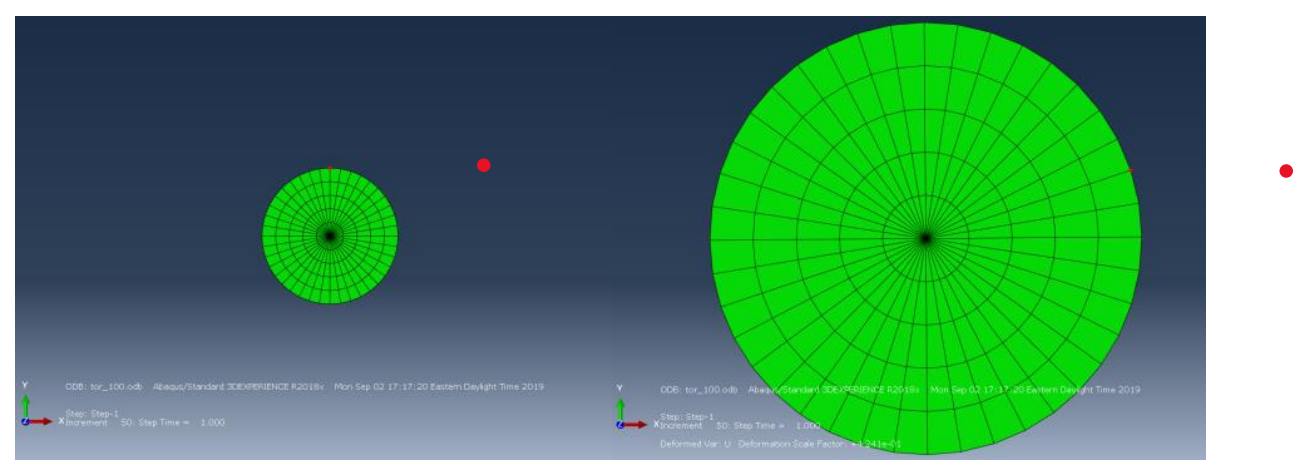

Figure 4.6 Node Displacement (red dot at top of circle on left is rotated clockwise on right)

The node at the top of the circle appeared to only move in the $\mathrm{x}$ direction. This was due to the fact that as the circle rotated, it was also expanding. The node moved horizontally relative to the point $\left(\mathrm{x}_{2}, \mathrm{y}_{2}, \mathrm{z}_{2}\right.$ from start to finish. Since the circle was constantly expanding, the top of the circle was also increasing in the y direction (Figure 4.6). The displacement compared to the top of the circle showed that there was relative vertical displacement as predicted using classical and modified theory of torsion. 
As the axial rotation (twist) of the cylinder increased between 0 and 0.2 rad, the strain tended to increase, between 0 and $0.0025 \%$, with an increasing gradient (Figure 4.7). Radial expansion strain therefore had a non-linear relationship to the axial rotation.

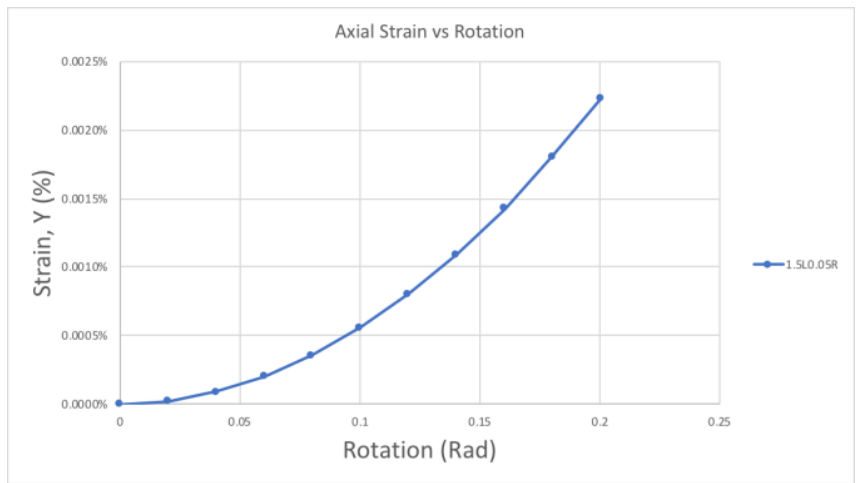

Figure 4.7 Axial Strain vs Axial Rotation for Static Torsion Loading Analysis of a Solid Cylinder

Similarly, for a cylinder with plastic steel properties, as the axial rotation of the cylinder increases between 0 and $0.5 \mathrm{rad}$, the strain tends to increase, between 0 and $0.25 \%$, (Figure 4.8 ) the radial expansion is increasing with a higher gradient as rotation increases.

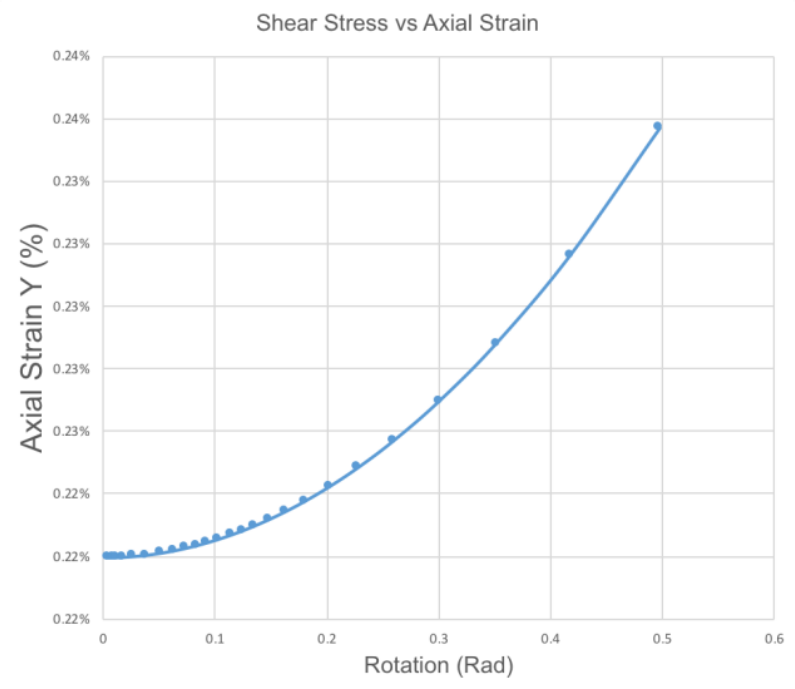

Figure 4.8 Axial Strain vs Axial Rotation for Dynamic Torsion Loading test of a Solid Cylinder 
The amount of strain caused by twisting was greater in magnitude for the cylinder with plastic (non-linear) properties (Fig. 4.8) compared with the linear elastic cylinder model (Fig. 4.7). The strain in Figure 4.8 was ten times greater in magnitude than in Figure 4.7.

\subsection{Constant B verified by FE Analysis}

B can be solved when equation 17 is rearranged and the displacement, $\Delta$ (U3) is divided by rotation, $\varphi$. For the case of a single cylinder with specified geometry, as axial rotation and axial displacement increased in the model, B remained the same value. Emperical paramter/constant B was either negative or positive depending on the negative or positive axial displacement of the model. B was shown to be constant as torque and axial rotation increased. Constant $B$ changed when the model was given different geometrical properties for the cylinder (Figure 4.9). For model 1.5L0.05R, the constant B was - 1.25e-16.

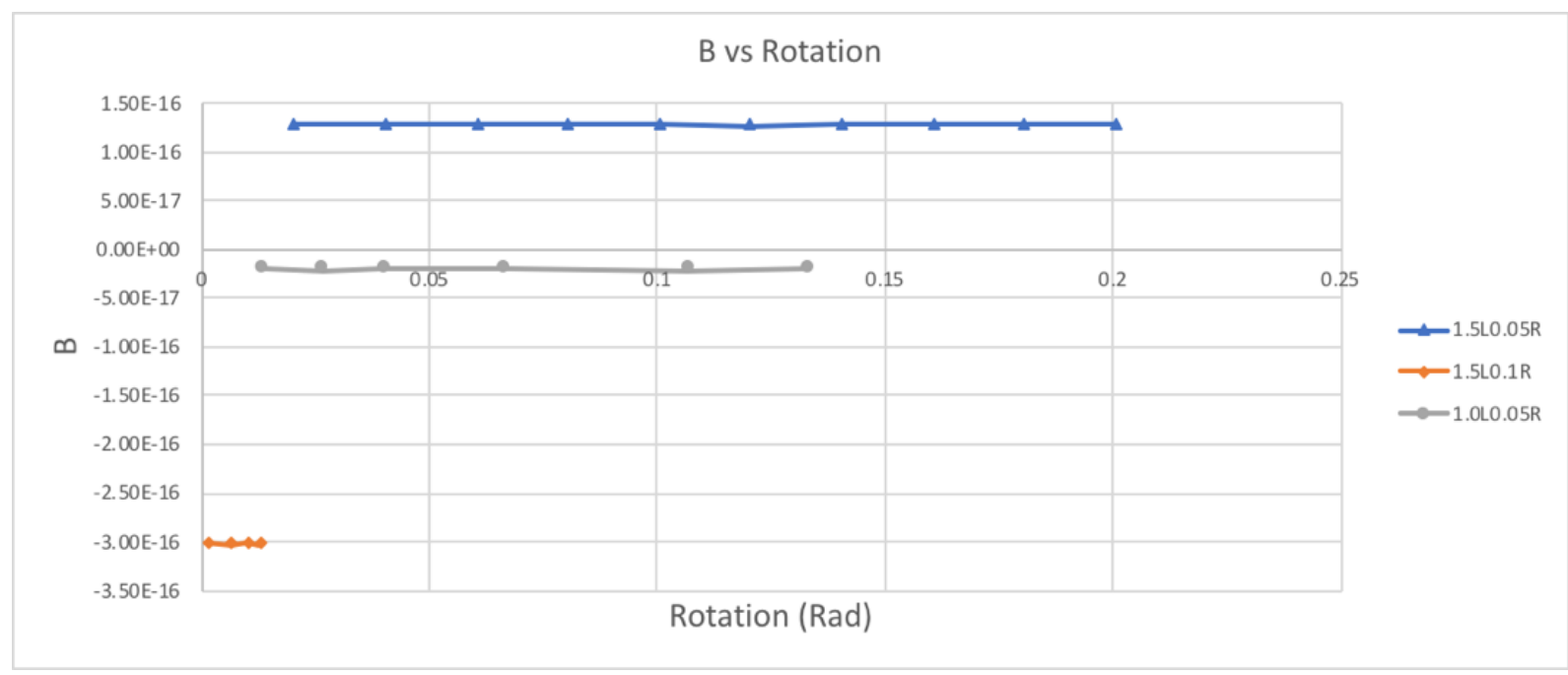

Figure 4.9 Constant B of Various Geometries

The relationship between the length and radius of the cylinder is yet to be expressed as a function. The geometric properties along with their corresponding constants B 
are presented in Table 1 through paramertic FE study of models having varying geomeric properties. It is noteworthy that when $\mathrm{L} / \mathrm{R}$ is the same, $\mathrm{B}$ is not similar in absolute magnitude. This would suggest that one of the parameters is more influencial on constant B than the other. When radius increased from 0.05 to 0.075 with $\mathrm{L}$ constant, B increased by a factor of 17.21. When length (L) increased from 1.5 to 2 with radius kept constant, B increased by a magnitude of 2.53 . Therefore, radius (R) played a more influencial role than L. This may be due to the fact that torsional shear stress is directly related to the $\mathrm{R}$ of a circle and that torsion constant $\mathrm{J}$ is dependent on $\mathrm{R}^{4}$.

Table 1 - Geometric Properties of Various Test Cylinder Compared to Constant B

\begin{tabular}{|c|c|c|c|c|}
\hline $\begin{array}{c}\text { Length } \\
\mathbf{L}(\mathbf{m})\end{array}$ & $\begin{array}{c}\text { Radius } \\
\mathbf{R}(\mathbf{m})\end{array}$ & $\mathbf{L} / \mathbf{R}$ & $\mathbf{( L / R ) ^ { 2 }}$ & $\begin{array}{c}\text { Empirical } \\
\text { parameter/constant } \\
\mathbf{B} \text { (m/rad) }\end{array}$ \\
\hline $\mathbf{1 . 5}$ & 0.1 & 15 & 225 & $-3.0225 \mathrm{E}-16$ \\
\hline $\mathbf{1}$ & 0.05 & 20 & 400 & $2.0544 \mathrm{E}-17$ \\
\hline $\mathbf{1 . 5}$ & 0.075 & 20 & 400 & $-3.5388 \mathrm{E}-16$ \\
\hline $\mathbf{1 . 5}$ & 0.05 & 30 & 900 & $1.2823 \mathrm{E}-16$ \\
\hline $\mathbf{2}$ & 0.05 & 40 & 1600 & $3.233 \mathrm{E}-16$ \\
\hline
\end{tabular}

Equation 17 was rearranged to solve for B and the FE model values for the study of a solid cylinder with plastic steel properties coudnot corroborate that B is a constant. As $\mathrm{N}$ and $\varphi$ increased, B increased overall, which meant that this method of testing for steel cylinders produced results that were incompatible with the modified theorem predictions. This result was expected given the fact that that the classical and modified theory were based on elastic properties. Even in cases where the cylinder was stressed within it's elastic range, the cylinder did not have a linear relationship between axial rotation and axial displacement. 


\subsection{Constant $\lambda$ Verified by FE Analysis}

The displacement was initially discribed using equation 15 as a trial. Analysis of the FE model data had shown that $B$ has a direct linear relationship to axial displacement. It is simply the displacement divided by the rotation ( $\mathrm{m} / \mathrm{rad})$. Therefore, $\lambda$ must be 1 if the equation is an accurate representation of $B$.

Therefore equations for FE model 1.5L0.05R is expressed as:

$$
\begin{aligned}
& \Delta=-1.28 \times 10^{-16} \varphi \\
& N=\frac{A E \varphi}{-1.28 \times 10^{-16} \mathrm{~L}}
\end{aligned}
$$

\subsection{Axial Force Induced by Applied Torque on Fixed Node}

Axial force was recorded at a reference point at the base of the cylinder. The boundary condition was set at the reference point to resist all forces and moments in every direction (fixed support). Specifically, it is the only point on the cylinder which resisted axial force RF3 in the FE model. When torque was applied to the cylinder, an axial reaction force was induced at the fixed support (Figure 4.10).

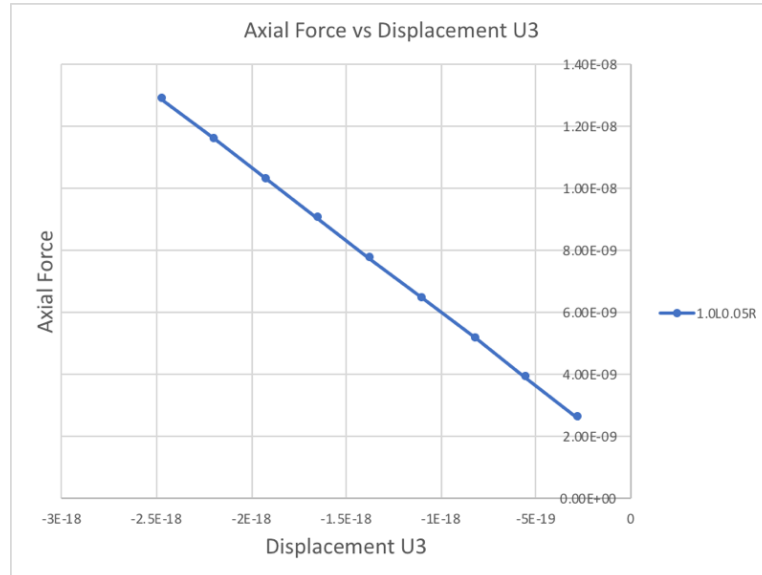

Figure 4.10 Axial Force Induced by Torsion for Static Torsion Loading Analysis of a Solid Cylinder 
The axial force increased in tension as axial displacement, U3 increased in magnitude (Fig. 4.10). For FE model 1.0L0.05R, the magnitude of axial force at $100 \mathrm{kNm}$ was $1.29 \mathrm{e}-08 \mathrm{~N}$. As torque acted on the cylinder, tension was induced internally, and the support reacted in tension. Oppositely in cases such as FE model $1.5 \mathrm{~L} 0.5 \mathrm{R}$, the axial displacement was $2.57 \mathrm{e}-17 \mathrm{~m}$ with an axial reaction force of -3.6e-09 $\mathrm{N}$ when 100 $\mathrm{kNm}$ torsion was applied. In each case, the relationship between axial force and axial displacement was linear as described using classical mechanics of solids as shown in Eq. 18.

Given the model axial forces and Equation 18, it is possible to predict the U3 axial displacement. The predicted axial displacement using modified theory, U3 is compared with the U3 recorded in the model in Figure 4.11. The predicted axial displacement (U3_Pred) is $75 \%$ of the recorded value in ABAQUS. This discrepancy may be attributed to the warping and lead to inconclusivenes that the cylinder shortend or elongated due to tension as the upper and lower face displaced equally and oppositely in U3 direction.

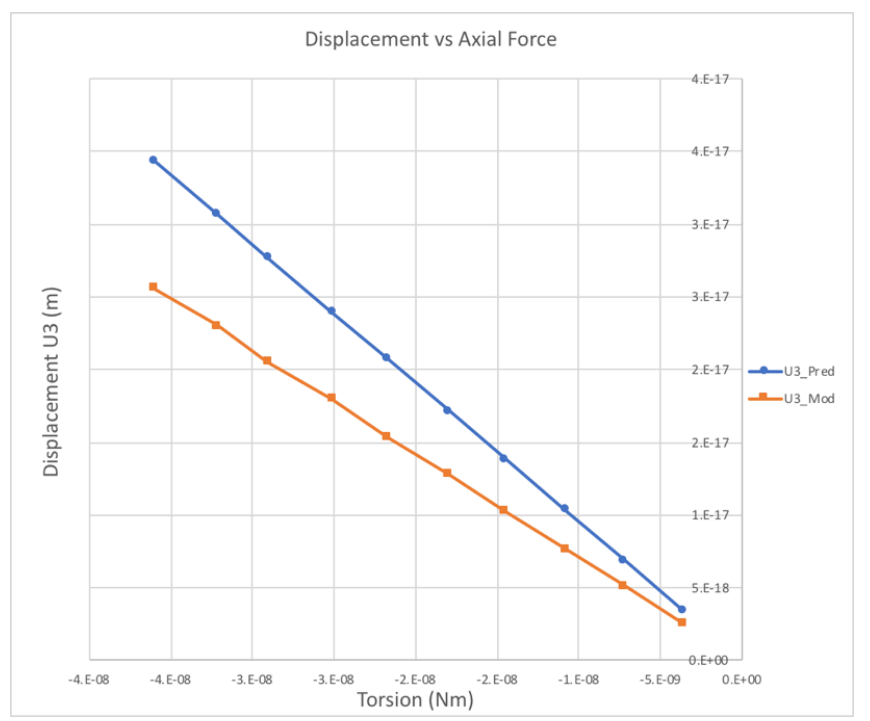

Figure 4.11 Test 1.5L0.05R - Displacement vs Axial Force for Static Torsion Loading Analysis of a Solid Cylinder 


\subsection{Constant $\gamma$ Verified by FE Analysis}

As rotation was recorded for each static FE models, it was possible to evaluate $\gamma$. Using the torque applied (T), and the recorded rotation ( $\phi)$, in every test model, $\gamma$ resulted as 0.3846 . This result confirmed that $\gamma$ did not rely on geometric properties but was related to the modulus of elasticity (E) and shear modulus (G).

This is further bolstered by the fact that Equation 24 can be rearranged to:

$$
\varphi=\left(\frac{\lambda}{\gamma \mathrm{E}}\right) * \frac{\mathrm{TL}}{J}, \text { where } \mathrm{G}=\frac{\mathrm{E}}{2(1+v)} \text { and } \frac{\mathrm{TL}}{\varphi \mathrm{J}}
$$

Taking Equation 26 and solving for $\frac{\lambda}{\gamma}$ :

$$
\frac{\lambda}{\gamma}=2(1+v)
$$

When $\lambda=1$, and the Poisson's ratio, $v=0.3, \gamma=0.3846$, as predicted in all the models. It is apparent that $\gamma$ is related to shear modulus (G) and Poisson's ratio.

When taking Equations 32 and 24 into consideration:

$$
\gamma=\frac{\lambda}{2(1+v)} \text { and } \varphi=\frac{\mathrm{TL}}{\mathrm{GJ}} \frac{\lambda}{\gamma 2(1+v)}
$$

$\gamma$ cancels the additional term derived in equation 24 and the equation based on classical theory for angle of twist of a solid cylindrical shaft (Eq. 3) is shown to be true:

$$
\varphi=\frac{\mathrm{TL}}{\mathrm{GJ}}
$$

The axial rotation (twist) equation for a solid cylinder expressed as Eq. 3 depends on the torque, length of cylinder, shear modulus and polar moment of inertia. It is still 
possible for axial displacement to occur at axial angle of rotation predicted in classical theoretical models.

\subsection{Shear Stress Induced by Applied Torque on Cylinder Face}

The developed maximum shear stress in FE model is presented in Fig. 4.12. Fig. 4.13 compares the maximum shear stress developed at the outer edge of the cylinder from classical theory and modified theorem. For FE model 1.5L0.05R, the maximum shear stress predicted by the classical theory was $5.093 \mathrm{e} 08 \mathrm{~N} / \mathrm{m}^{2}$ while FE model shear stress was $4.62 \mathrm{e} 08 \mathrm{~N} / \mathrm{m}^{2}$. For FE model $1.5 \mathrm{~L} 0.05 \mathrm{R}$, the overall rate of convergence is $90 \%$ and this discrepancy might be attributed to the effect induced axial force and axial displacement. In another case, FE model 1.5L0.1R, the shear stress in the model is $110 \%$ beyond the classical theory predicted shear stress (Figure 4.13 ).

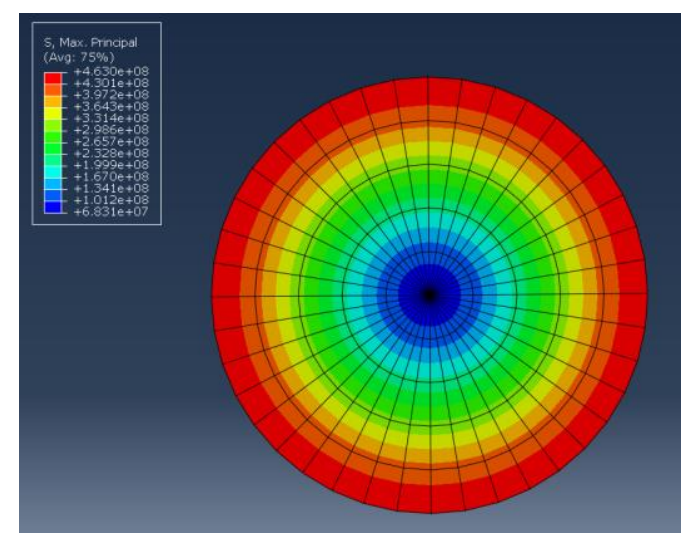

Figure 4.12 Max Principle Shear Stress Developed About a Cylinder

The shear stress values obtained from the model deviated $\pm 10 \%$ from the classical model prediction meaning that other factors were causing the discrepency such mesh size (had not reached optimization). In cases of higher FE Model predicted shear stress, this also might be due to the development of added residual stresses due to mesh geometry. 


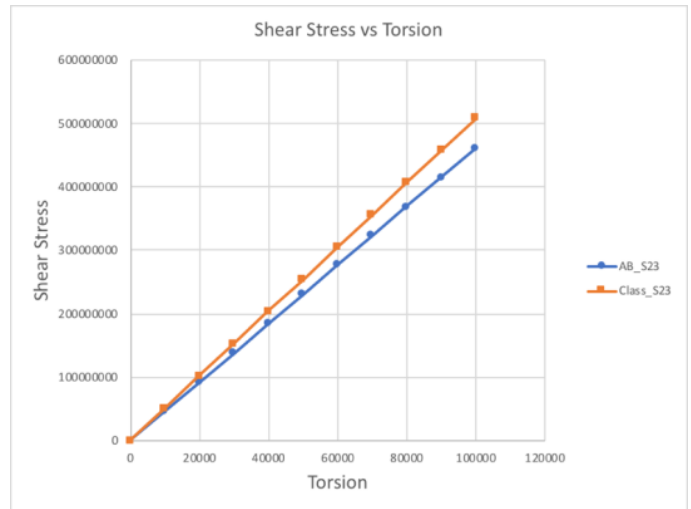

Figure 4.13 Shear Stress vs Applied Torsion (1.5L0.05R) for Static Torsion Loading Analysis of a Solid Cylinder

Now that through B is known and axial force is given, it should be possible to solve for torsion to verify if Equation 14 of the modified theorem of torsion is valid. It was shown using the data from the model and applying constants $B, \gamma$ and $\lambda$, the predicted shear stress based on modified theorem is $2 \%$ of the shear stress caculated from the the model. This means that either the axial force is not correct or another factor must be implemented to acount for the low magnitude in shear stress. Since the model axial force is extracted from the base of the cylinder it is possible that the axial reaction force is lower at the base because the angle of twist at the base is not as high compared to the front free face of the cylinder (due to non-uniform axial stress distribution along the length, which needs to be studied further).

For the dynamic model with non-linear plastic properties assigned to the steel cylinder, the integration point of an element was chosen at the outermost edge of the cylinder to record the shear Stress and maximum von-Mises Stress in the cylinder (Figure 4.14). The cylinder was rotated incrementally up to $0.5 \mathrm{rad}$ with torque, $\mathrm{T}=$ $50 \mathrm{kNm}$. Once the cylinder reached stress of $150 \mathrm{MPa}$, the gradient of stress increased along with rotation, as expected with given material plastic properties. This model showed that the dynamic incremental step loading induced stresses that were weaker 
in magnitude compared to static single step FE models. For FE model 1.5L0.05R, the shear stress was $284 \mathrm{MPa}$ and $462 \mathrm{MPa}$ for the dynamic and static analyses, respectively.

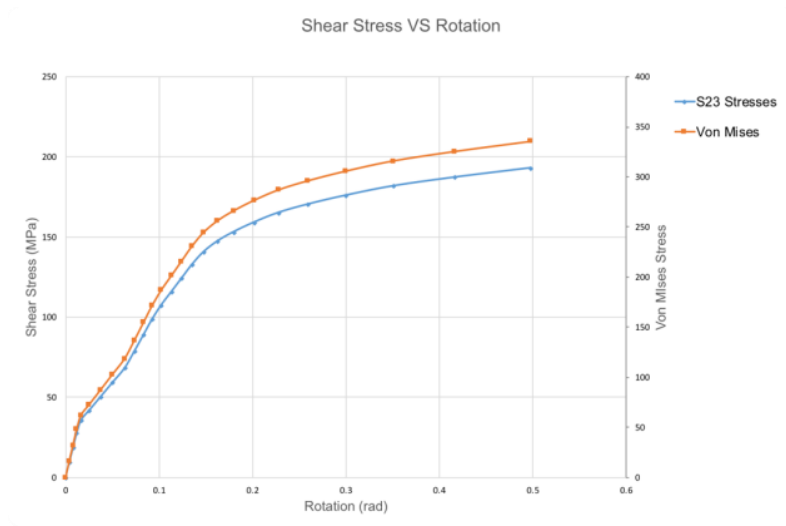

Figure 4.14 Shear and Von Mises Stress (MPA) vs Rotation Caused by Torsion for Dynamic Torsion Loading Analysis of a Solid Cylinder

\subsection{Helical Pattern of Cylinder}

It was confirmed from FE models (Fig. 4.5), that if one end of a cylinder was fixed and the other end is free with an applied torque, the cylinder rotated axially and developed a helical pattern. When a line was drawn (red line) at the top of the cylinder it gradually followed the curve about the surface of the cylinder (Figure 4.15).

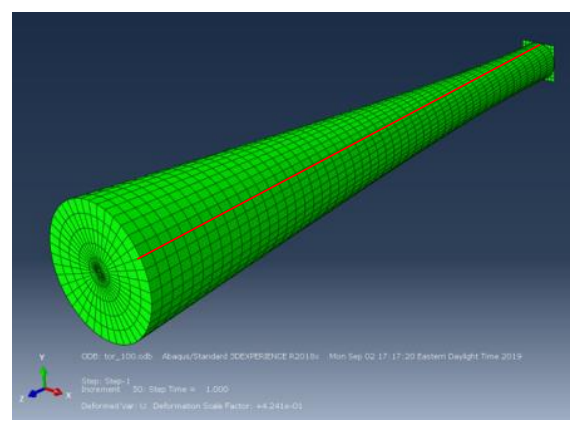

Figure 4.15 Helical Pattern of Twisted Cylinder 


\section{CHAPTER 5}

\section{CONCLUSIONS AND RECOMMENDATIONS}

\subsection{General}

Using finite element (FE) analysis software, a study was conducted on the torsional behaviour of a canitiver solid steel cylinder subjected to troque applied to the free end. . The cylinders were assembled between two discrete rigid plates and underwent linear and non-linear simple static and dynamic torsion analyses to verify shear stress and axial rotation predictions made using a modified theory of torsion developed by Shirali and Hossain (2019) that took into account the effect of axial deformation neglected in classical theory. Results including axial displacement, axial force , axial rotation (twist) and shear stress were collected from theFE models and compared with classical theoretical calculations. The values obtained in the FE model were used to determine empirical parameters/constants introducced in modified theroy (such as $B, \lambda$, and $\gamma$ ) that took into account the eefect of axial displacement and force developed in the cylinder dur to appliction of torsional loading.

\subsection{Conclusions}

The following conclusions were drawn from the study:

- When torque was applied to the free face of the solid cylinder, the face rotated nd a helical pattern was generated along the length of the cylinder. The helix rotation increased and draw the face of the cylinder inward and created axial shortening. FE analyses confrmed the developent of axial deformtion (shortening or elongation) and axial sress/strain (which is neglected in classical theory) as assumed in modified theory. However, the modified theorem did not take into account warping and radial expansion. Nonetheless 
torsion had an effect on the length of the cylinder whether due to U3 (axial) displacement or warping/radial expansion.

- Based on Shirali and Hossain (2019), axial displacement was related to the axial force. The predicted axial force was found to be around $75 \%$ of that predicted from FE model.

- The equations for predicting shear stress, axial forc and axial rotation were derived, which introdcuced empirical prameters $(B, \lambda$, and $\gamma$ ) were determined through FE parametric studies and performance of equations were validated.

- It was also shown that the axial displacement had a linear relationship with the axial rotation. B was found to be independent of axial rotation and torque but dependent on geometric properteis of the cylinder (length, radius and their ratio). The values of $\mathrm{B}$ as function of these geomtric parametrs ar presented in tabuar form.

- An equation for axial rotation $(\varphi)$ was derived by modifying clasical theory of torsion of a solid cylinder by incoporating prameter/ constant $\gamma$. It was shown that $\gamma$ was related to material properties (Poisson's ratio, $v$ and the shear modulus). It was also shown from FE analyses of axial rotation that $\gamma$ was equal to $1 /(2+v)$, which meant that the classical theory of rotation is not affected by $\gamma$. Models using material properties with different Poisson's ratios should be tested for further confirmation. Cylinders with non-linear plastic material properties did not show linear relationship between rotation and torque.

- The modifed equtions (based on modified theory) can predict axial stress/strain, toisonal shear stress and axial rotation (twist) with better accuracy than equations derived based on classicial theory. Howvwer, classical theroy can be used to predict toisonal shear stress and axial rotation in the elastic range with their assumptions and limitations. 


\subsection{Recommendations for Further Studies}

The following recommendations are made for further research studies:

- Add more material properties to predict more accurate behaviour of steel in elastic and plastic range.

- Develop FE models of various shapes and sizes to corroborate findings for constant $\mathrm{B}$ and axial force $\mathrm{N}$.

- Develop FE models similar to this study with added temperature conditions in ABAQUS.

- Conduct study with changing Poisson's ratio to show the dependence of $\gamma$ on the modulus of elasticity.

- Alter boundary conditions of the cylinder face to limit radial expansion which, may induce different axial displacement values or limit the effects of torsional warping in the solid cylinder.

- Analyse FE models where torsion will be applied to the the cylinder by other means than through tying discrete rigid plates to the cylinder face or coupling the reference point to the free cylinder face.

- Do modeling by placing cylinder between two plates that will be fixed on both sides. Apply torsion to the middle of the cylinder and see the effect of both support reactions on axial shortening.

- Carryout experimental investigations to validate the modified theory as this study are limited to FE modeling and analyses. 


\section{APPENDIX A}

Technical Report: Modified Torsion Theorem Considering Axial Deformation by Shirali. O., and Hossain, K. M. A. (2019) 


\title{
Technical Report: Modified Torsion Theorem Considering Axial Deformation
}

\author{
By \\ Shirali. O. and Hossain K. M.A. \\ Department of Civil Engineering \\ Ryerson University
}

Toronto, Ontario, Canada

(C) Khandaker M. Anwar Hossain, 2019 


\section{Introduction:}

In this article, I would like to explore the behavior of materials during a torsion moment. Despite the general idea that a torsion moment imposes shear force on an element; I would like to show how torsion moment imposes tension force as well.

Most of us have had an experience in wringing a wet cloth. In order to wring a cloth out, we hold our hands at each end of the cloth then twist our hands in opposite directions. When we wring a cloth out, we can observe force which pulls our hands together.

Another example is the nut and bolt. When put together, the nut is screwed by following a path designed into the bolt. As this nut follows up the bolt and presses the element in between them, tension is created through this action of torsion.

The following example explains how torsion moment implies tension forces on the element. There are two parallel rings which are connected together with cables. The lower ring has no movement and upper ring can only rotate around on perpendicular axe to the ring plane. Cables are the same size, parallel to each other and do not interfere with each other during torsion (Fig 1).

$\mathrm{n}=$ number of cables

$\mathrm{R}=$ radius of ring

$\mathrm{M}_{(\mathrm{T})}=$ torsion
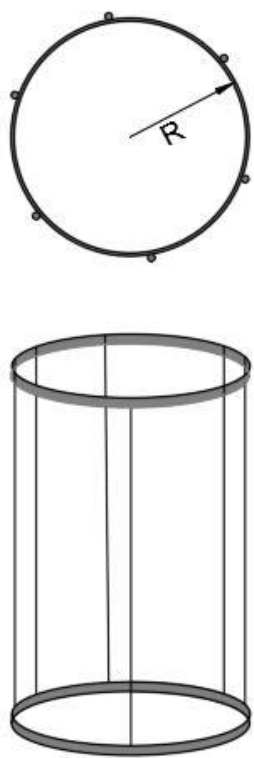

Fig 1

When $\mathrm{M}_{(\mathrm{T})}$ applies to the upper ring; it pulls all cables and creates tension force (F) in each cable (Fig 2). 
$\mathrm{F}=$ tension force along each cable due to torsion.

$\theta=$ angle of twist

$F_{(N)}=$ Axial force perpendicular to the ring plane.

$F_{(T)}=$ Force parallel to upper ring plane.

$\mathrm{F}_{(\mathrm{T})}=\mathrm{F} \operatorname{Sin}(\theta)$

$\mathrm{F}_{(\mathrm{N})}=\mathrm{F} \operatorname{Cos}(\theta)$

$\mathrm{M}_{(\mathrm{T})}=\mathrm{n} \mathrm{F}_{(\mathrm{T})} \mathrm{R}=\mathrm{n} \mathrm{FR} \operatorname{Sin}(\theta)$

Tension force in each cable is as follows:

$\mathrm{F}=\mathrm{M}_{(\mathrm{T})} /[\mathrm{n} \mathrm{R} \operatorname{Sin}(\theta)]$

(Other cables are not shown for clarity)

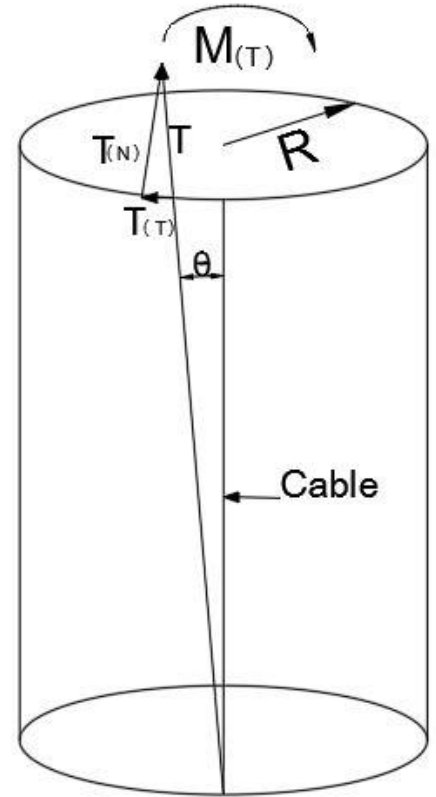

(Fig 2) 


\section{Torsion Theorem:}

This theorem has been based on the two ideas as follows:

A straight line on the element, perpendicular to the plane of torsion, will move to a new location due to torsion and the pattern of new curved line is a function of the Helix Equilibrium.

$$
\mathrm{p}=\left\{\begin{array}{l}
\mathrm{x}=\operatorname{Ar} \operatorname{Cos}(\gamma \varphi) \\
\mathrm{y}=\mathrm{Ar} \operatorname{Sin}(\gamma \varphi) \\
\mathrm{z}=\mathrm{z}_{1}+\mathrm{B} \varphi^{\lambda}
\end{array}\right.
$$

Or
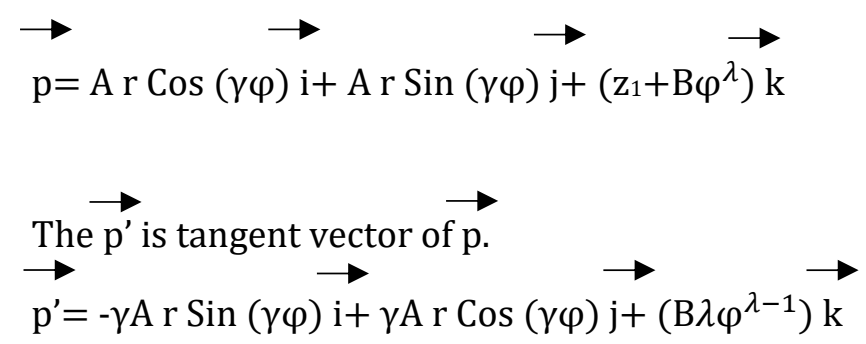

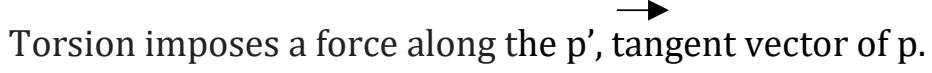
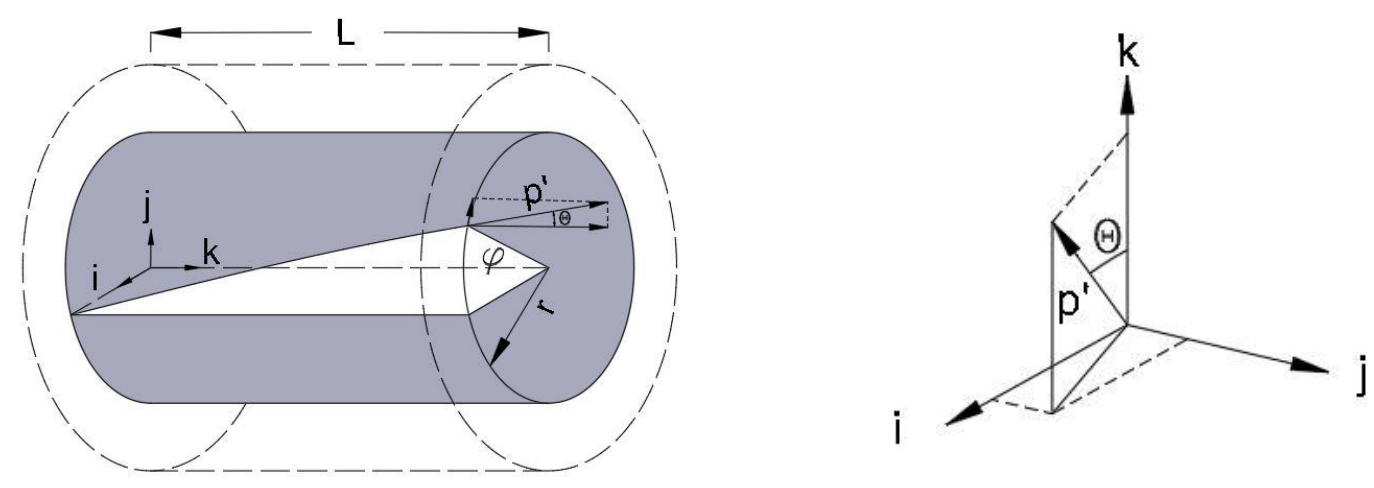

(Fig 3) 
$\theta$ is angle between $\overrightarrow{\mathrm{p}^{\prime}}$ and $\overrightarrow{\mathrm{k}}$.

$\operatorname{Cos}(\theta)=\frac{\left|\mathrm{p}^{\prime} \cdot \mathrm{k}\right|}{\left|\mathrm{p}^{\prime}\right| \cdot|\mathrm{k}|}$

$\left|p^{\prime} \cdot \mathrm{k}\right|=-(\gamma \mathrm{A}) \mathrm{r} \operatorname{Sin}(\gamma \varphi)^{*} 0+(\gamma \mathrm{A}) \mathrm{r} \operatorname{Cos}(\gamma \varphi)^{*} 0+\mathrm{B} \lambda \varphi^{\lambda-1}$

$\left|p^{\prime}\right|=\sqrt{(\gamma r)^{2}+\left(B \lambda \varphi^{\lambda-1}\right)^{2}}$

$|\mathrm{k}|=1$

$\operatorname{Cos}(\theta)=\frac{\mathrm{B} \lambda \varphi^{\lambda-1}}{\sqrt{(\mathrm{A} \gamma \mathrm{r})^{2}+\left(\mathrm{B} \lambda \varphi^{\lambda-1}\right)^{2}}}$

$\operatorname{Sin}(\theta)=\frac{A \gamma r}{\sqrt{(A \gamma r)^{2}+\left(B \lambda \varphi^{\lambda-1}\right)^{2}}}$

The straight line $\mathrm{OM}$ is located on the element. Element is fixed at point $\mathrm{O}$ fixed and able to move/rotate at the point M (Fig. 4).

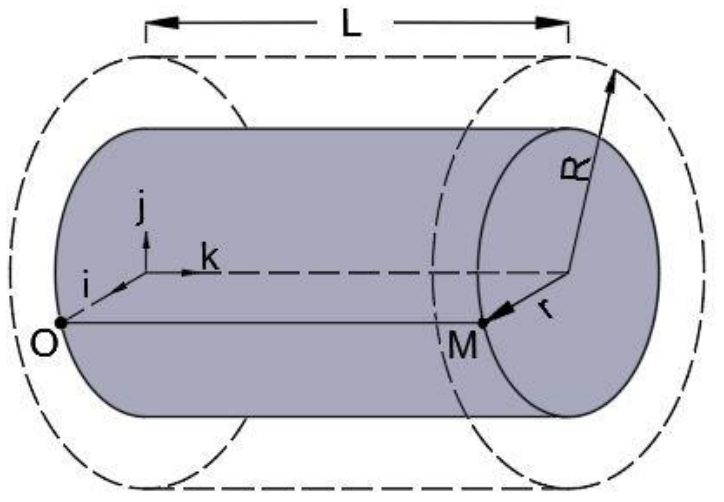

Fig. 4 
$\mathrm{OM}$ is an arbitrary point on the element (radius $\mathrm{r}$ ). Torsion relocates point $\mathrm{M}$ to the $\mathrm{M}^{\prime}$ (Fig. 5).

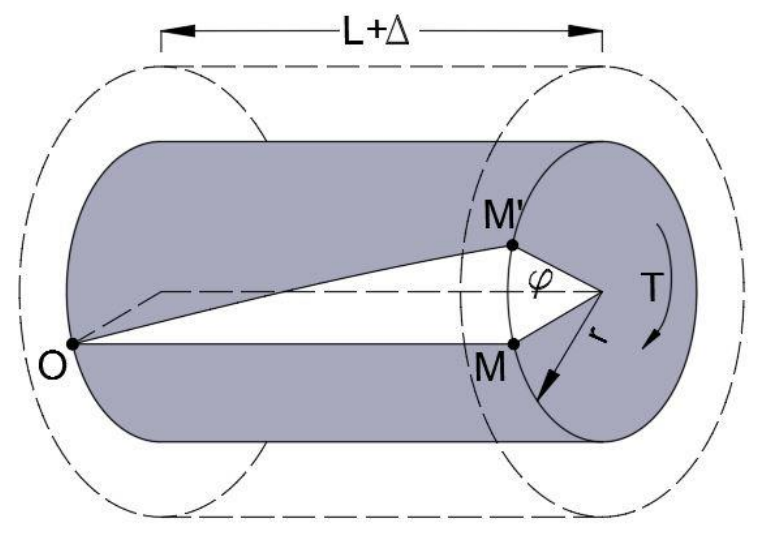

Fig. 5

$\mathrm{T}=$ Torsion moment

$A=$ coefficient

$\gamma=$ coefficient (to be verified in lab)

$\mathrm{B}=$ coefficient(to be verified in lab)

$\mathrm{r}=$ Radius at point $\mathrm{M}$

$\varphi=$ angle of twist at the point M (See Fig. 5)

$$
M=\left\{\begin{array}{l}
x_{M}=r \\
y_{M}=0 \\
z_{M}=L
\end{array}\right.
$$$$
\mathrm{M}^{\prime}=\left\{\begin{array}{l}
\mathrm{x}_{\mathrm{M}^{\prime}}=\operatorname{ArCos}(\varphi) \\
\mathrm{y}_{\mathrm{M}^{\prime}}=\operatorname{Ar} \operatorname{Sin}(\gamma \varphi) \\
\mathrm{z}_{\mathrm{M}^{\prime}}=\mathrm{L}+\mathrm{B} \lambda \varphi^{\lambda-1}
\end{array}\right.
$$ 
The angle of twist at the point 0 is zero $(\varphi=0)$

$$
\mathrm{O}=\left\{\begin{array}{l}
\mathrm{x}_{0}=\mathrm{r} \\
\mathrm{y}_{0}=0 \\
\mathrm{z}_{0}=0
\end{array} \quad \longrightarrow \quad \mathrm{O}^{\prime}=\left\{\begin{array}{l}
\mathrm{x}_{0^{\prime}}=\mathrm{A} \mathrm{r} \\
\mathrm{y}_{0^{\prime}}=0 \\
\mathrm{z}_{0^{\prime}}=0
\end{array}\right.\right.
$$

The points $\mathrm{O}$ and $\mathrm{O}^{\prime}$ are coincident; therefore $\mathrm{A}=1$.

$$
\begin{aligned}
& \overrightarrow{\mathrm{p}}=\mathrm{r} \operatorname{Cos}(\gamma \varphi) \overrightarrow{\mathrm{i}}+\mathrm{r} \operatorname{Sin}(\gamma \varphi) \mathrm{j}+\left(\mathrm{z}_{1}+\mathrm{B} \lambda \varphi^{\lambda-1}\right) \overrightarrow{\mathrm{k}} \\
& \overrightarrow{\mathrm{p}^{\prime}}=-\gamma \mathrm{r} \operatorname{Sin}(\gamma \varphi) \overrightarrow{\mathrm{i}}+\gamma \mathrm{r} \operatorname{Cos}(\gamma \varphi) \overrightarrow{\mathrm{j}}+\left(\mathrm{B} \lambda \varphi^{\lambda-1}\right) \overrightarrow{\mathrm{k}} \\
& \mathrm{p}^{\prime} \text { is the tangent vector } \vec{\longrightarrow} \rightarrow \\
& \theta=\text { Angle between } \mathrm{p}^{\prime} \text { and } \mathrm{k}
\end{aligned}
$$

$$
\begin{aligned}
& \operatorname{Cos}(\theta)=\frac{\mathrm{B} \lambda \varphi^{\lambda-1}}{\sqrt{(\gamma \mathrm{r})^{2}+\left(\mathrm{B} \lambda \varphi^{\lambda-1}\right)^{2}}} \\
& \operatorname{Sin}(\theta)=\frac{\gamma \mathrm{r}}{\sqrt{(\gamma \mathrm{r})^{2}+\left(\mathrm{B} \lambda \varphi^{\lambda-1}\right)^{2}}}
\end{aligned}
$$

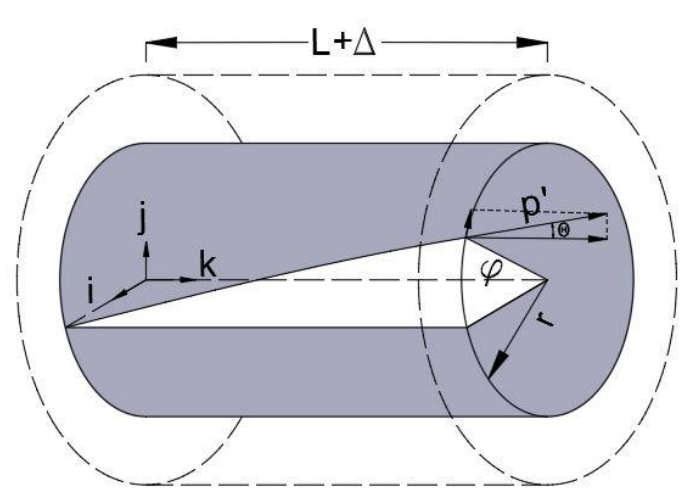

Fig. 6 

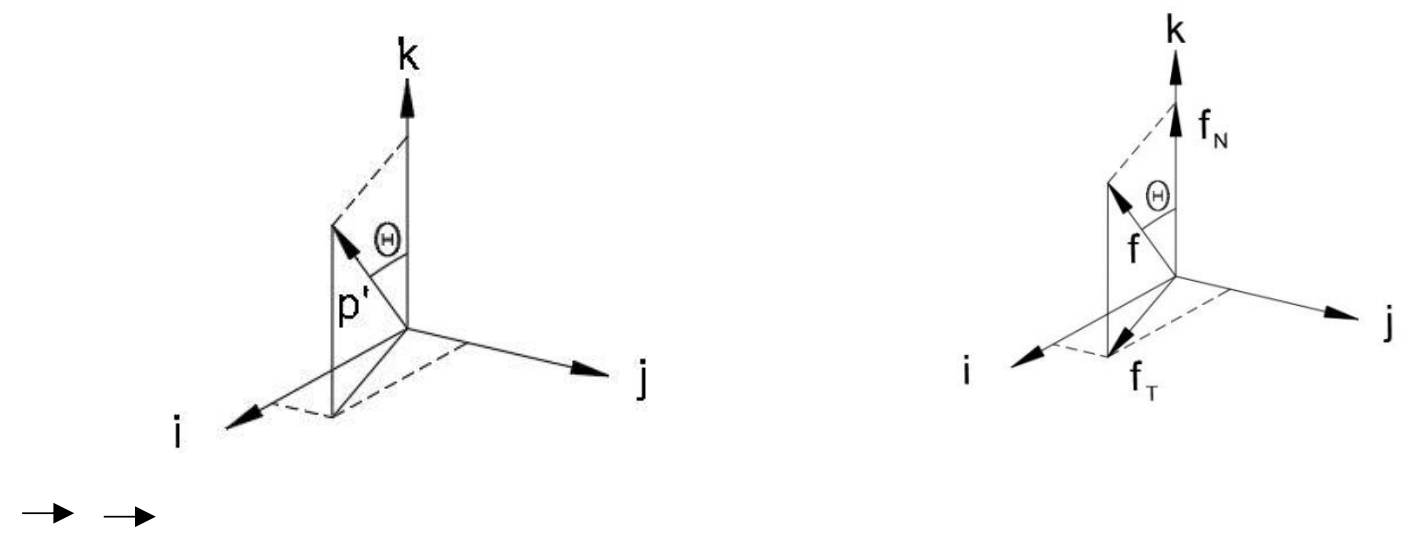

$\mathrm{f} \| \mathrm{p}^{\prime}$

We may calculate the length of curved line according following formula:

$$
\begin{aligned}
& S=\int_{0}^{S} d s \\
& d s=\sqrt{(d x)^{2}+(d y)^{2}+(d z)^{2}} \\
& S=\int_{0}^{\varphi} \sqrt{\left(\frac{\partial x}{\partial \varphi}\right)^{2}+\left(\frac{\partial z}{\partial \varphi}\right)^{2}+\left(\frac{\partial z}{\partial \varphi}\right)^{2}} d \varphi
\end{aligned}
$$

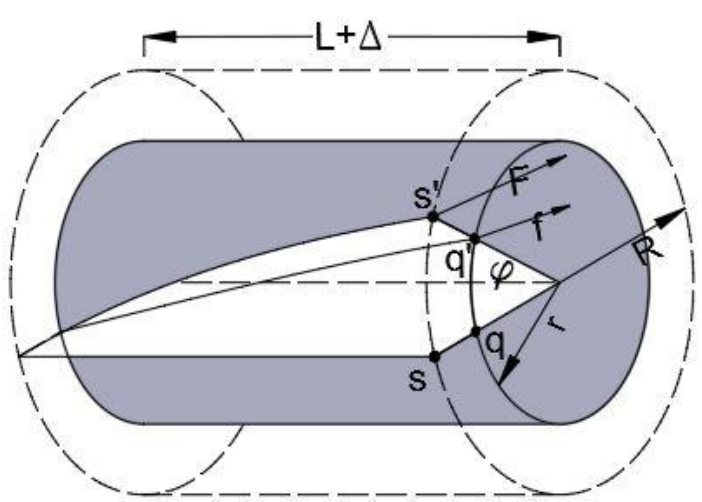

Fig 7

$$
\begin{aligned}
& s s^{\prime}=\int_{0}^{\varphi} \sqrt{(-\gamma R \operatorname{Cos}(\gamma \varphi))^{2}+(\gamma R \operatorname{Sin}(\gamma \varphi))^{2}+\left(\mathrm{B} \lambda \varphi^{\lambda-1}\right)^{2}} d \varphi \\
& s s^{\prime}=\varphi \sqrt{(\gamma R)^{2}+\left(\mathrm{B} \lambda \varphi^{\lambda-1}\right)^{2}} \\
& q q^{\prime}=\int_{0}^{\varphi} \sqrt{(-\gamma r \operatorname{Cos}(\gamma \varphi))^{2}+(\gamma r \operatorname{Sin}(\gamma \varphi))^{2}+\left(\mathrm{B} \lambda \varphi^{\lambda-1}\right)^{2}} d \varphi \\
& q q^{\prime}=\varphi \sqrt{(\gamma r)^{2}+\left(\mathrm{B} \lambda \varphi^{\lambda-1}\right)^{2}}
\end{aligned}
$$


$\Delta_{\mathrm{R}}=\mathrm{ss}^{\prime}$

$\Delta_{\mathrm{R}}=\varphi \sqrt{(\gamma \mathrm{R})^{2}+\left(\mathrm{B} \lambda \varphi^{\lambda-1}\right)^{2}}$

$\Delta_{\mathrm{r}}=\mathrm{qq}^{\prime}$

$\Delta_{\mathrm{r}}=\varphi \sqrt{(\gamma \mathrm{r})^{2}+\left(\mathrm{B} \lambda \varphi^{\lambda-1}\right)^{2}}$

$\Delta_{\mathrm{r}} / \Delta_{\mathrm{R}}=\sqrt{(\gamma \mathrm{r})^{2}+\left(\mathrm{B} \lambda \varphi^{\lambda-1}\right)^{2}} /$

$\sqrt{(\gamma \mathrm{R})^{2}+\left(\mathrm{B} \lambda \varphi^{\lambda-1}\right)^{2}}$

F: force at point s'(See Fig. 7)

f: force at point q'(See Fig. 7)

Force is linear function of the displacement. Therefore; we can say $\mathrm{f} \propto \Delta_{\mathrm{r}}$ and $\mathrm{F} \propto \Delta_{\mathrm{R}}$ $\mathrm{f} / \mathrm{F}=\sqrt{(\gamma \mathrm{r})^{2}+\left(\mathrm{B} \lambda \varphi^{\lambda-1}\right)^{2}} / \sqrt{(\gamma \mathrm{R})^{2}+\left(\mathrm{B} \lambda \varphi^{\lambda-1}\right)^{2}}$

The force due to torsion (f) is a parallel with vector tangent $p^{\prime}$.

f $\| p^{\prime}$

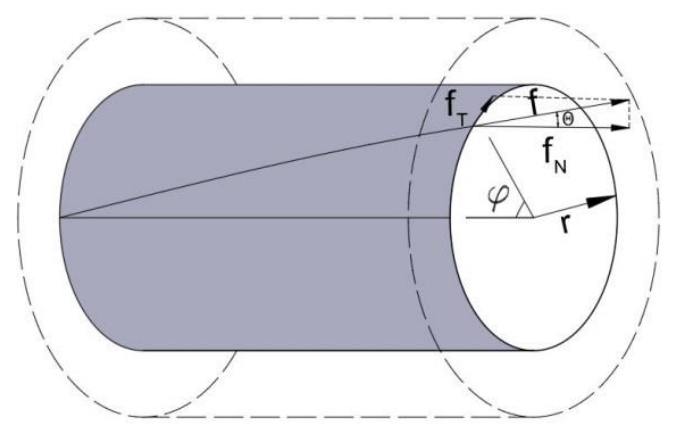

Fig. 8

$\overrightarrow{\mathrm{f}_{\mathrm{T}}}=\overrightarrow{\mathrm{f}} \operatorname{Sin}(\theta)$

(See Fig. 7)

$\operatorname{Sin}(\theta)=\frac{\gamma \mathrm{r}}{\sqrt{(\gamma \mathrm{r})^{2}+\left(\mathrm{B} \lambda \varphi^{\lambda-1}\right)^{2}}}$ 


$$
\begin{aligned}
& \mathrm{f}_{\mathrm{T}}=\left[\mathrm{F} \sqrt{(\gamma \mathrm{r})^{2}+\left(\mathrm{B} \lambda \varphi^{\lambda-1}\right)^{2}} / \sqrt{(\gamma \mathrm{R})^{2}+\left(\mathrm{B} \lambda \varphi^{\lambda-1}\right)^{2}}\right] \frac{\gamma \mathrm{r}}{\sqrt{(\gamma \mathrm{r})^{2}+\left(\mathrm{B} \lambda \varphi^{\lambda-1}\right)^{2}}} \\
& \mathrm{f}_{\mathrm{T}}=\gamma \mathrm{r} \mathrm{F} / \sqrt{(\gamma \mathrm{R})^{2}+\left(\mathrm{B} \lambda \varphi^{\lambda-1}\right)^{2}}
\end{aligned}
$$

(See Fig. 9)

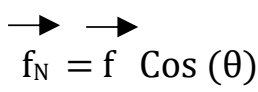

(See Fig. 7)

$$
\begin{aligned}
& \operatorname{Cos}(\theta)=\frac{\mathrm{B} \lambda \varphi^{\lambda-1}}{\sqrt{(\gamma \mathrm{r})^{2}+\left(\mathrm{B} \lambda \varphi^{\lambda-1}\right)^{2}}} \\
& \mathrm{f}_{\mathrm{N}}=\left[\mathrm{F} \sqrt{(\gamma \mathrm{r})^{2}+\left(\mathrm{B} \lambda \varphi^{\lambda-1}\right)^{2}} / \sqrt{(\gamma \mathrm{R})^{2}+\left(\mathrm{B} \lambda \varphi^{\lambda-1}\right)^{2}}\right]^{*} \frac{\mathrm{B} \lambda \varphi^{\lambda-1}}{\sqrt{(\gamma \mathrm{r})^{2}+\left(\mathrm{B} \lambda \varphi^{\lambda-1}\right)^{2}}} \\
& \mathrm{f}_{\mathrm{N}}=\mathrm{B} \lambda \varphi^{\lambda-1} \mathrm{~F} / \sqrt{(\gamma \mathrm{R})^{2}+\left(\mathrm{B} \lambda \varphi^{\lambda-1}\right)^{2}}
\end{aligned}
$$

(See Fig. 10)

$$
\begin{aligned}
& \mathrm{T}=\int_{0}^{\mathrm{R}} 2 \pi \mathrm{f}_{\mathrm{T}} \mathrm{rdr} \\
& \mathrm{T}=\int_{0}^{\mathrm{R}} 2 \pi \mathrm{r} \gamma \mathrm{rF} / \sqrt{(\gamma \mathrm{R})^{2}+\left(\mathrm{B} \lambda \varphi^{\lambda-1}\right)^{2}} * \mathrm{r} \\
& \mathrm{dr} \\
& \mathrm{T}=2 \pi \gamma \mathrm{F} / \sqrt{(\gamma \mathrm{R})^{2}+\left(\mathrm{B} \lambda \varphi^{\lambda-1}\right)^{2}} \int_{0}^{\mathrm{R}} \mathrm{r}^{3} \mathrm{dr} \\
& \mathrm{T}=2 \pi \gamma \mathrm{F} / \sqrt{(\gamma \mathrm{R})^{2}+\left(\mathrm{B} \lambda \varphi^{\lambda-1}\right)^{2}}\left[\mathrm{r}^{4} / 4\right]_{0} \mathrm{R} \\
& \mathrm{T}=\mathrm{R}^{4} \pi \gamma \mathrm{F} /\left(2 \sqrt{(\gamma \mathrm{R})^{2}+\left(\mathrm{B} \lambda \varphi^{\lambda-1}\right)^{2}}\right)
\end{aligned}
$$

(Eq:1)

$\mathrm{J}=\pi \mathrm{R}^{4} / 2$
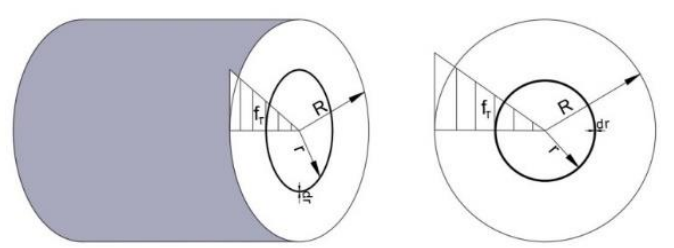

Fig. 9

$\mathrm{T}=\gamma \mathrm{JF} / \sqrt{(\gamma \mathrm{R})^{2}+\left(\mathrm{B} \lambda \varphi^{\lambda-1}\right)^{2}}$ 
$\mathrm{N}=$ Total Normal force on the cross section

$\mathrm{f}_{\mathrm{N}}=\mathrm{B} \lambda \varphi^{\lambda-1} \mathrm{~F} / \sqrt{(\gamma \mathrm{R})^{2}+\left(\mathrm{B} \lambda \varphi^{\lambda-1}\right)^{2}}$

$\mathrm{N}=\int_{0}^{\mathrm{R}} 2 \pi \mathrm{r} \mathrm{f}_{\mathrm{N}} \mathrm{dr}$

$\mathrm{N}=\int_{0}^{\mathrm{R}} 2 \pi \mathrm{r} * \mathrm{~B} \lambda \varphi^{\lambda-1} \mathrm{~F} / \sqrt{(\gamma \mathrm{R})^{2}+\left(\mathrm{B} \lambda \varphi^{\lambda-1}\right)^{2}}$

$\mathrm{dr}$

$\mathrm{N}=2 \pi^{*} \mathrm{~B} \lambda \varphi^{\lambda-1} \mathrm{~F} / \sqrt{(\gamma \mathrm{R})^{2}+\left(\mathrm{B} \lambda \varphi^{\lambda-1}\right)^{2}} \int_{0}^{\mathrm{R}} \mathrm{r}$

$\mathrm{dr}$

$\mathrm{N}=2 \pi^{*} \mathrm{~B} \lambda \varphi^{\lambda-1} \mathrm{~F} / \sqrt{(\gamma \mathrm{R})^{2}+\left(\mathrm{B} \lambda \varphi^{\lambda-1}\right)^{2}}[\mathrm{r}$

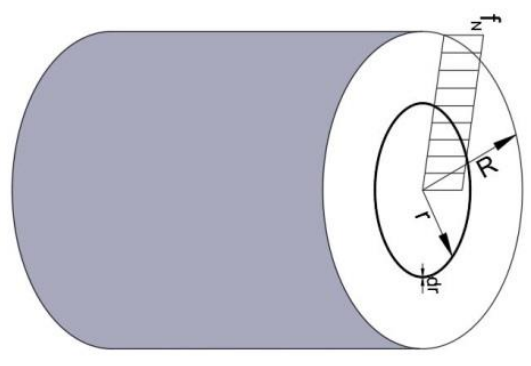

$2 / 2]_{0} \mathrm{R}$

$\mathrm{N}=\pi R^{2} \mathrm{~B} \mathrm{~F} / \sqrt{(\gamma \mathrm{R})^{2}+\left(\mathrm{B} \lambda \varphi^{\lambda-1}\right)^{2}}$

(Eq:2)

Resolving Eq:1 and Eq:2, we are able to conclude that:

$\mathrm{T}=\frac{\gamma}{2\left(\mathrm{~B} \lambda \varphi^{\lambda-1}\right)} \mathrm{R}^{2} \mathrm{~N}$

(Eq:3)

$\Delta=$ The torsion shortening

$\Delta=\mathrm{B} \varphi^{\lambda} \quad$ (Eq:4)

From strength of material, we know

$\Delta=\mathrm{NL} / \mathrm{AE} \quad, \mathrm{A}=$ cross section area

(Eq:5)

Fig. 10 
Resolving Eq:4 and Eq:5, we are able to conclude that:

$\mathrm{B}=\mathrm{NL} /\left(\mathrm{AE} \varphi^{\lambda}\right) \quad(\mathrm{Eq}: 6)$

Resolving Eq:3 and Eq:6

$\mathrm{T}=\frac{\gamma}{\left.2\left(\lambda \mathrm{NL} /\left(\operatorname{AE} \varphi^{\lambda}\right)\right) * \varphi^{\lambda-1}\right)} \mathrm{R}^{2} \mathrm{~N}$

$\mathrm{T}=\frac{\gamma \varphi}{2(\lambda L)} \mathrm{AE} \mathrm{R}^{2}, \mathrm{~A}=\pi \mathrm{R}^{2}$

$\mathrm{T}=\frac{\gamma \varphi}{2(\lambda L)} \pi \mathrm{R}^{4} \mathrm{E} \quad, \mathrm{J}=\pi \mathrm{R}^{4} / 2$

$\mathrm{T}=\frac{\gamma \varphi}{(\lambda L)} \mathrm{JE}$

$\varphi=\left(\frac{\lambda}{\gamma \mathrm{E}}\right) * \frac{\mathrm{TL}}{J} \quad$ (Eq: 7$)$

From strength of material, we know

$\varphi=\frac{\mathrm{TL}}{G J} \quad(\mathrm{Eq}: 8)$

$\mathrm{G}=\frac{\mathrm{E}}{2(1+v)} \quad, v=0.3$ (Poisson's ratio)

With comparing Eq:7 and Eq:8, we may conclude that

$$
\begin{aligned}
& \frac{\lambda}{\gamma}=2(1+v) \\
& \left.\frac{\lambda}{\gamma}=2.6 \quad \text { (Eq: } 9\right)
\end{aligned}
$$

$\gamma$ is a coefficient for angle of twist $(\varphi)$ which it can be considered as 1 for linear displacement. Therefore; $\lambda=2.6$

$$
\begin{aligned}
& \operatorname{Cos}(\theta)=\frac{2.6 \mathrm{~B} \varphi^{1.6}}{\sqrt{(\mathrm{r})^{2}+\left(2.6 \mathrm{~B} \varphi^{1.6}\right)^{2}}} \text { (Eq: 10) } \\
& \left.\operatorname{Sin}(\theta)=\frac{\mathrm{r}}{\sqrt{(\mathrm{r})^{2}+\left(2.6 \mathrm{~B} \varphi^{1.6}\right)^{2}}} \text { (Eq: } 11\right)
\end{aligned}
$$


From Eq: 6

$\mathrm{B}=\mathrm{NL} /\left(\mathrm{AE} \varphi^{2.6}\right)$

From Eq: 2

$\mathrm{N}=\pi R^{2} \mathrm{~B} \mathrm{~F} / \sqrt{(\mathrm{R})^{2}+\left(2.6 \mathrm{~B} \varphi^{1.6}\right)^{2}}$

From Eq: 1

$\mathrm{T}=\pi \mathrm{R}^{4} \mathrm{~F} /\left(2 \sqrt{(\mathrm{R})^{2}+\left(2.6 \mathrm{~B} \varphi^{1.6}\right)^{2}}\right)$

From Eq: 3

$\mathrm{T}=\frac{1}{2\left(2.6 \mathrm{~B} \varphi^{1.6}\right)} \mathrm{R}^{2} \mathrm{~N}$

From Eq: 3 and 6

$\varphi=\frac{\mathrm{TL}}{G J}$

\section{Conclusion:}

Torsion produces axial force and change the total length of member (torsion shortening). The amount of axial force is a function angle of twist as follows:

$$
\mathrm{N}=\operatorname{AEB} \varphi^{2.6} / \mathrm{L}
$$

Eq: 12

Also, the pattern of helix is function of angle of twist as well. The formula indicates for each angle of twist; the longitudinal fibers of element follow a unique helix pattern. 


\section{REFERENCES}

Billington, E.W., (1977), Non-Linear mechanical response of various metals II. Permanent length changes in twisted tubes, Journal of Physics D: Applied Physics, Vol. 10 , p. $533-552$.

Hibbler, R.C. (2011). Mechanics of Materials, $8^{\text {th }}$ Edition, Pearson Prentice Hall, 1 Lake Street, Upper Saddle River, NJ, 07458.

Shirali, O. and Hossain, K.M.A. (2019), Modified Torsion Theorem Considering Axial Deformation, Technical Report, Department of Civil Engineering, Ryerson University p. 1-12.

Montheillet, F., Cohen, M., Jonas, J.J., (1984). Axial Stresses and Texture Development during Torsion Testing of $\mathrm{AL}, \mathrm{Cu}$ and $\alpha$-Fe. Acta Metallurgica, Vol. 32, Issue 11, November 1984, P. 2077-2089. 